\title{
Automatic interpretation and writing report of the adult waking electroencephalogram.
}

\section{AUTHOR(S):}

Shibasaki, Hiroshi; Nakamura, Masatoshi; Sugi, Takenao; Nishida, Shigeto; Nagamine, Takashi; Ikeda, Akio

\section{CITATION:}

Shibasaki, Hiroshi ...[et al]. Auto matic interpretation and writing report of the adult waking electroencephalogram.. Clinical neurophysiology 2014, 125(6): 1081-1094

\section{ISSUE DATE:}

2014-06

URL:

http://hdl.handle.net/2433/187820

\section{RIGHT:}

(C) 2014 International Federation of Clinical Neurophysiology. Published by Elsevier Ireland Ltd.; This is not the published version. Please cite only the published version.; この 論文は出版社版でありません。引用の際には出版社版をご確認ご利用ください。 


\title{
Automatic interpretation and writing report of the adult waking electroencephalogram ${ }^{\dagger}$
}

\author{
Hiroshi Shibasaki $^{a^{*}}$, Masatoshi Nakamura ${ }^{b}$, Takenao Sugi ${ }^{b}$, Shigeto \\ Nishida $^{c}$, Takashi Nagamine ${ }^{a, d}$, Akio Ikeda a, e
}

a Department of Neurology and Human Brain Research Center, Kyoto University Graduate School of Medicine, Kyoto, Japan

b Saga University Graduate School of Science and Engineering, Saga, Japan

c Department of Computer and Communication Engineering, Fukuoka Institute of Technology, Fukuoka, Japan

d Department of Systems Neuroscience, School of Medicine, Sapporo Medical University, Sapporo, Japan

o Department of Epilepsy, Movement Disorders and Physiology, Kyoto University Graduate School of Medicine, Kyoto, Japan

\section{* Corresponding author:}

Hiroshi Shibasaki

Emeritus Professor, Kyoto.University Graduate School of Medicine, Kyoto, Japan

Tel: $+81-75-701-1451$

E-mail: shib@kuhp.kyoto-u.ac.jp

† This article is based on the presentation and demonstration at the 
Hands-on-Workshop on EEG in the $5^{\text {th }}$ Asia-Oceania Congress of Clinical Neurophysiology held in Bali, Indonesia on August 28-31, 2013.

\section{Highlights}

1. A computer-assisted system for automatic, systematic and comprehensive interpretation of the adult waking EEG was developed for the first time.

2. This new system can provide a written report of the adult waking EEG which is in good conformity with the results of visual inspection of the same record by qualified electroencephalographers (EEGers).

3. This system can be applied to the clinical diagnosis of EEG as a supplementary tool to the EEGer's visual inspection and to the education of EEG trainees and EEG technicians. 


\begin{abstract}
Automatic interpretation of EEG has so far been faced with significant difficulties because of a large amount of spatial as well as temporal information contained in the EEG, continuous fluctuation of the background activity depending on changes in the subject's vigilance and attention level, the occurrence of paroxysmal activities such as spikes and spike-and-slow-waves, contamination of the EEG with a variety of artifacts, and the use of different recording electrodes and montages. Therefore, previous attempts of automatic EEG interpretation have been focused only on a specific EEG feature such as paroxysmal abnormalities, delta waves, sleep stages and artifact detection. As a result of a long-standing cooperation between clinical neurophysiologists and system engineers, we report for the first time on a comprehensive, computer-assisted, automatic interpretation of the adult waking EEG. This system analyzes the background activity, intermittent abnormalities, artifacts and the level of vigilance and attention of the subject, and automatically presents its report in written form. Besides, it also detects paroxysmal abnormalities, and evaluates the effects of intermittent photic stimulation and hyperventilation on the EEG. This system of automatic EEG interpretation was formed by adopting the strategy that the qualified EEGers employ for the systematic visual inspection. This system can be used as a supplementary tool for the EEGer's visual inspection, and for educating EEG trainees and EEG technicians.
\end{abstract}


Keywords: Automatic interpretation of EEG, quantitative EEG analysis, background activity of EEG, posterior dominant rhythm, spike detection, automatic writing of EEG report.

\section{Introduction}

Electroencephalogram (EEG) is conventionally interpreted by electroencephalographers (EEGers) through the visual inspection. If EEG can be automatically interpreted, it is expected to be more quantitative and more objective than the visual inspection, and evidence-based as against experience-based. However, in strong contrast to electrocardiogram (EKG) which can be automatically interpreted and has been universally applied for practical use in the clinical setting, the quantitative analysis of EEG which is necessary for its automatic interpretation is faced with great difficulties due to multiple reasons. First, EEG contains an astronomical amount of spatial as well as temporal information. Secondly, the background activity of EEG tends to fluctuate moment to moment depending on the subject's condition such as the vigilance and attention level. Thirdly, EEG often contains various forms of paroxysmal abnormalities such as spikes and spike-and-slow"waves which have to be distinguished from the background activities as well as from various artifacts. Fourthly, EEG is often contaminated with artifacts of biological source such as electromyogram (EMG), EKG, pulsation (plethysmogram), blinks, eye movements and sweating, and artifacts of technical origin, in particular electrode artifacts. 
Fifthly, both bipolar and referential montages are commonly used so that the two montages can complement each other for providing the correct spatial information. These factors have made it difficult to practically apply the automatic interpretation system of EEG, if any, for clinical purposes (Anderson and Doolittle, 2010 for review). As a result, the previous attempts of automatic EEG interpretation have been focused only on a specific EEG feature such as paroxysmal abnormalities, delta waves, sleep stages and artifact detection.

Automatic spike detection on either the scalp-recorded or depth-recorded EEG in epilepsy patients has been explored by a number of investigators (Gotman and Gloor, 1976; Gotman, 1982, 1985 for review; Frost, 1985 for review; Wilson et al., 1999; Wilson and Emerson 2002 for review; van Putten, 2003; von Ellenrieder et al., 2012; Ayoubian et al., 2013). Automatic analyses of sleep stages by using EEG data have also been implemented by many investigators

(Inoue et al., 1982; da Rosa and Paiva, 1993; Jobert et al., 1994; Strungaru and Popescu, 1998; Anderer et al., 2010; Jensen et al., 2010; Ronzhina et al., 2012; Brignol et al., 2013). Quantitative analysis of a specific EEG feature was applied to the patients with ischemic stroke mainly for obtaining its prognostic information (Nuwer et al., 1987; Nagata, 1989; Claassen et al., 2004; Finnigan et al., 2004, van Putten et al., 2004a, 2004b; Finnigan et al., 2007; Sheorajpanday et al., 2009, 2011; Cloostermans et al., 2011; Finnigan and van Putten, 2013 for review). Quantitative EEG analysis was also applied for the diagnostic aid of traumatic brain injury (Nuwer et al., 2005), psychiatric diseases (Leuchter et al., 2012), cognitive 
disorders (Melissant et al., 2005; Buscema et al., 2007; Rossini et al., 2008;

Caso et al., 2012; Kim et al., 2012), and behavioral disorders (Mathewson et al., 2012).

When an experienced EEGer reads EEG, it appears as if he/she interprets each page of the record by just taking a quick look at it. However, its process actually involves a series of systematic analysis of spatial and temporal information about all frequency components that constitute the EEG, although the actual method employed by each EEGer might differ among EEGers to a considerable extent. Therefore, the present authors thought that it might be possible to establish a computer-assisted system for automatic interpretation of the whole EEG by adopting the strategy that the EEGers employ for the visual inspection.

To the authors' knowledge, a computer-assisted system for making automatic, systematic and comprehensive interpretation of the whole EEG and for writing the report has not been successfully achieved. In a majority of the previously reported studies, the target of automatic analysis was restricted to a specific EEG feature such as the posterior dominant rhythm (Nakamura et al., 1985; Marcuse et al., 2008; Lodder and van Putten, 2011) and the scalp topography of slow waves (Matsuoka et al., 1978). Recently Lodder and van Putten attempted a quantitative analysis of the background activities of the adult waking EEG, and achieved the results which were in relatively good agreement with the consensus results of EEGers' visual inspection (Lodder and van Putten, 2013).

Since early 1980's, the present authors, through close collaboration of 
clinical neurophysiologists with system engineers, have been engaged in the development of a computer-assisted system for automatic, systematic, comprehensive interpretation of the adult waking EEG and for writing its report (Nakamura et al., 1985, 1992, 1993; 1996; Bai et al., 2000a).

The aim

of the study was to automatically present a written report of EEG which was in good agreement with the report obtained by the EEGer's visual inspection. This paper will review each process involved in the development of the present automatic EEG interpretation system in reference to literatures related to the respective process.

\section{Extraction of features of EEGer's visual inspection and quantitative scoring}

The information about each frequency component, which is analyzed by the systematic visual inspection of EEGers, is formed of (1) the posterior dominant rhythm: as to whether it exists or not, and its organization and symmetry if it exists, peak frequency and its symmetry, amplitude and its symmetry, and the antero-posterior distribution, (2) beta rhythm: amplitude and its symmetry, (3) theta waves: location and duration, (4) delta waves: location and duration, and (5) non-dominant alpha rhythm (alpha rhythm not attributed to the posterior dominant alpha rhythm): distribution and duration (Table 1). Based on the method of visual inspection employed by qualified EEGers among the present authors (initially HS, and later HS and $\mathrm{AI}$, each parameter of each frequency band was quantified and scored into four categories; namely normal and three different degrees of abnormality 
(mild, moderate and marked) (Table 1).

'Posterior dominant rhythm' was defined as a rhythmic activity usually in the alpha frequency band in healthy adults which is maximally located at the occipital or parietal region and is seen predominantly in time (Nakamura et al., 1985; Marcuse et al., 2008; Lodder and van Putten, 2011). The posterior dominant rhythm is the most essential component of the waking background EEG, and thus this activity should be attended first whenever reading a waking EEG record. Therefore, this activity was the first target of the authors' series of investigation, and its automatic analysis was successfully achieved (Nakamura et al, 1985). More recently, Lodder and van Putten also reported an automated analysis of the posterior dominant rhythm with a three-component curve-fitting technique (Lodder and van Putten, 2011). In the present paper, the 'background activity' is defined as any EEG activity representing the setting in which a given normal or abnormal pattern appears and from which such pattern is distinguished (Noachtar et al., 1999 for terminology).

In the present automatic analysis system, if the record was acquired in a completely resting condition with the subject's eyes closed, complete absence of the posterior dominant rhythm in an adult EEG was judged markedly abnormal ('lack of posterior dominant rhythm') and was quantitatively scored 3 (Table 1). Regarding the lack of the posterior dominant rhythm, however, a particular attention is required for interpreting the results of automatic interpretation, because it is well known that, even in healthy adults, alpha rhythm can be completely replaced by the low amplitude beta 
rhythm in a highly attended condition, for example during the state of eyes open. In the present system of automatic interpretation, the distinction of 'lack of posterior dominant rhythm' from physiological blocking of the dominant rhythm due to an increased attention level was made possible by calculating the amount of slow waves during the corresponding segment of EEG. In the pathological conditions associated with 'lack of posterior dominant rhythm', a various amount of slow waves is present in the background activity, with an exception of the electrocerebral silence which is encountered in the condition of brain death. If there were eye blinks just before the segment, the eye blink artifacts were also taken into account for making the judgment of physiological blocking of the alpha rhythm (see Section 5 for automatic detection of the eye blink artifacts). It is important to note that, if the results of automatic interpretation suggest 'lack of posterior dominant rhythm', the finding should be carefully confirmed by qualified EEGers before making the final judgment.

According to a glossary of terms proposed by the International Federation of Clinical Neurophysiology (IFCN) (Noachtar et al, 1999), 'organization' of the posterior dominant rhythm was defined as 'the degree to which physiologic EEG rhythms conform to certain ideal characteristics displayed by a majority of subjects in the same age group, without personal or family history of neurologic and psychiatric diseases, or other illnesses that might be associated with dysfunction of the brain'. In the present system, abnormality of organization was scored into three categories; poorly organized (score 1), disorganized (score 2) and markedly disorganized (score 
3) (Table 1).

It should be noted that, even in the adult waking EEG, the posterior dominant rhythm can be slower than the alpha frequency band in pathological conditions. Thus the fact that the posterior dominant rhythm is not necessarily in the alpha frequency band has to be taken into account for the automatic EEG interpretation system. In the present system, the peak frequency of the posterior dominant rhythm in healthy adults was judged normal when it was $9 \mathrm{~Hz}$ or above, mildly abnormal (score 1) when it was between 8 and $9 \mathrm{~Hz}$ ('slow alpha rhythm'), and moderately abnormal (score 2) when it was $8 \mathrm{~Hz}$ or less but more than $6 \mathrm{~Hz}$ (Table 1). As for the asymmetry of the peak frequency of the posterior dominant rhythm between two sides, it was judged asymmetric when there was a left-to-right difference by $0.5 \mathrm{~Hz}$ or more. It was judged mildly asymmetric (score 1) when the left-right difference was $0.5 \mathrm{~Hz}$ or more but less than $1.0 \mathrm{~Hz}$, moderately asymmetric (score 2) when the difference was $1.0 \mathrm{~Hz}$ or more but less than $2.0 \mathrm{~Hz}$, and markedly asymmetric (score 3 ) when it was $2.0 \mathrm{~Hz}$ or more (Table 1).

Amplitude of the posterior dominant rhythm was judged abnormal when it exceeded $100 \mu \mathrm{V}$ in the referential derivation against the ipsilateral ear lobe reference. It was judged mildly abnormal (score 1) when it was 100 $\mu \mathrm{V}$ or larger but smaller than $130 \mu \mathrm{V}$, and moderately abnormal (score 2) when it was $130 \mu \mathrm{V}$ or larger (Table 1). The amplitude was judged to be significantly asymmetric when its left-right difference was $50 \%$ or more. It was judged mildly abnormal (score 1) when it was asymmetric by $50 \%$ or 
more but less than $60 \%$, moderately abnormal (score 2 ) when it was so by $60 \%$ or more but less than $80 \%$, and markedly abnormal (score 3 ) when it was $80 \%$ or more (Table 1 ). As for the anterior extension of the posterior dominant rhythm, the amplitude was calculated after automatically excluding the effect of activation of the ear lobe reference electrode by the posterior dominant rhythm and by taking into account the bipolar derivation. And it was judged mildly abnormal (score 1) when the posterior dominant rhythm extended to the frontal (F3, Fz, F4) or anterior temporal electrodes (F7, F8), and moderately abnormal (score 2) when it reached the fronto-polar electrodes (Fp1, Fp2) with low amplitude, and markedly abnormal (score 3) when it did so with high amplitude (Table 1).

Rhythmic activity of the beta frequency was judged abnormal when its amplitude as measured in the referential derivation against the ipsilateral ear lobe reference exceeded $50 \mu \mathrm{V}$ at any electrode (Table 1). The amplitude of beta rhythm was judged asymmetric when its left-right difference exceeded $50 \%$ between any pair of the homologous electrodes. It was judged mildly asymmetric (score 1) when the left-right difference was $50 \%$ or more but less than $60 \%$, moderately asymmetric (score 2 ) when it was $60 \%$ or more but less than $80 \%$, and markedly asymmetric (score 3 ) when it was $80 \%$ or more (Table 1 ).

As for the slow waves, the presence of activities of the theta frequency band was grouped into three degrees of abnormality depending on its proportional duration in time; mildly abnormal (score 1) when it was seen less than $5 \%$ of the total time, moderately abnormal (score 2 ) when it was 
seen $5 \%$ or more but less than $50 \%$ of the total time, and markedly abnormal (score 3 ) when it was seen $50 \%$ or more of the total time (Table 1 ). In the subjects of age over 65 , however, a short run of theta waves at the temporal electrodes was accepted physiological as far as its amount did not exceed $10 \%$ of the total time. Presence of activities of the delta frequency band at any electrode was always judged abnormal at least to a moderate degree. It was judged moderately abnormal (score 2) when it was seen less than $50 \%$ of the total time and markedly abnormal (score 3) when it was seen 50\% or more of the time (Table 1). In the present automatic interpretation system, distribution of the theta and delta waves over the head was automatically illustrated on an electrode map (Example data will be presented in Sections 7 and 9).

\section{Preparation of EEG data for quantitative analysis}

In contrast to the visual inspection of EEG which mainly adopts analysis of the time series, analysis of the frequency domain has been applied and proved more useful for the quantitative analysis (Nakamura et al., 1985; Nishida et al., 1986; Nuwer et al., 1987; Nakamura et al., 1992; Aurlien et al., 2004; Anderson and Doolittle, 2010 for review). The rationale for developing the present automatic interpretation system was based on an EEG model proposed by the authors' group (Nishida et al., 1986; Bai et al., 2000a). In this model, the amplitude information of EEG represented in the time domain was shown to be reliably obtained from the power spectrum in the frequency domain by the use of a Markov process amplitude model. 
At the initial stage of the present project when an 16-channel analog electroencephalograph was used for recording EEG, the data were acquired with a referential montage with respect to the ipsilateral ear lobe electrode as well as with the standard bipolar montage according to the International 10-20 Electrode System, with the time constant of $0.1 \sim 0.3 \mathrm{~s}$ and the low-pass filter of $60 \sim 120 \mathrm{~Hz}$. The conversion from the analog to digital data was done either from the data stored in a magnetic tape or from the pen-written data. In the early phase of the present system development, 10 artifact-free segments of $5 \mathrm{~s}$ long each were selected from the whole EEG, and the 10 segments data were digitized at a sampling rate of $50 \mathrm{~Hz}$ (Nakamura et al., 1985). This low sampling rate was utilized because the analysis at that time was made only for the activities of frequency below 25 Hz. Later the whole EEG was sectioned into consecutive segments of $5 \mathrm{~s}$ long each and processed for further analysis (Fig. 1) (see Section 9 for the updated procedure of analysis).

After the digital electroencephalograph became available for the clinical use, recording of EEG was made with a wide frequency response at a high sampling rate. And later the high frequency cut-off at $60 \mathrm{~Hz}$ was applied, and all the EEG data were analyzed with the sampling rate of $200 \mathrm{~Hz}$. Sixteen channels EEG against the ipsilateral ear lobe reference were subjected for the analysis, and the standard bipolar montage was referred to when necessary. The power spectrum of each EEG segment was calculated by the Fast Fourier Transform (FFT) (Cooly and Tukey, 1965) (Fig. 1, Fig. 2), and was subjected to the following quantitative analysis. 


\section{Construction of algorithm for calculating parameters of each frequency} band

In accordance with the quantitative data of visual inspection by the qualified EEGers (Table 1), algorithms for calculating parameteŕs of each frequency band were constructed as presented in Table 2 (Nakamura et al:, 1992). These algorithms were prepared so that the results could match those of the visual inspection by the qualified EEGers as closely as possible by using a least square method (Bjorck, 1996). As for the posterior dominant rhythm, first the peak frequency in the interval of $7.2 \cdot 13.0 \mathrm{~Hz}$ was searched at the left and right occipital electrodes $\left(\mathrm{O}_{1}\right.$ and $\mathrm{O}_{2}$, respectively). Then the power of the rhythmic activity within $\pm 1 \mathrm{~Hz}$ across the detected peak frequency, which is called 'dominant frequency band' in this paper, was measured at the occipital $(\mathrm{O})$ and parietal $(\mathrm{P})$ electrodes on each hemisphere. The power of the dominant frequency band at either the electrode $\mathrm{O}$ or $\mathrm{P}$, depending on whichever was larger, for each hemisphere was designated $\bar{S}_{d}$ for that hemisphere, and the rhythm in question was judged to be dominant in time when $\bar{S}_{d}$ was $10 \%$ or more of the total power $\left(\bar{S}_{T}\right)$ at that electrode (Equation 1.1). Then the maximum power within the dominant frequency band at all electrodes other than $\mathrm{O}$ and $\mathrm{P}$ (namely Fp, F, C, T) was designated as $\tilde{S}_{d}$. When $\bar{S}_{d}$ was equal to or larger than $\tilde{S}_{d}$, the rhythm in question was judged to have spatial dominance over the posterior region of the head (Equation 1.2). The threshold amplitude for the existence of the dominant rhythm was set to $10 \mu \mathrm{V}$ (Equation 1.3). Regarding the 
Equation 1.1 and 1.3, as explained above (Section 3), the amplitude information was estimated from the power spectrum based on the authors' EEG model which is expressed by the sinusoidal waves with the Markov process amplitude (Nishida et al., 1986; Bai et al., 2000a). If all of these three criteria were fulfilled, the posterior dominant rhythm was judged to exist in the analyzed segments (Table 2).

$$
\begin{aligned}
& \bar{S}_{d} / \bar{S}_{T} \geq 0.1 \\
& \bar{S}_{d} / \tilde{S}_{d} \geq 1.0 \\
& 10 \sqrt{\bar{S}_{d}} \geq 10 \mu \mathrm{V}
\end{aligned}
$$

Then other features of the posterior dominant rhythm were evaluated as follows. For scoring 'organization' of the posterior dominant rhythm, five parameters measured at either electrode $\mathrm{O}$ or $\mathrm{P}$, depending on which electrode $\overline{S_{d}}$ belongs to, were taken into account (Equation 2, Table 2).

$$
y_{d}=0.49+0.58 \sigma_{\alpha}-0.13 S_{\alpha}+4.82 \times 10^{-5}\left(S_{\alpha}\right)^{2}-0.41 S_{\alpha} / S_{T}+3.12 S_{\delta} / S_{T}
$$

This equation was formed by the linear combination of $\sigma_{\alpha}$ (standard deviation of the alpha rhythm), $S_{\alpha}$ (integrated power of the alpha rhythm), $S_{\alpha} / S_{T}$ (ratio of the integrated power of the alpha rhythm to that of all rhythms), and $S_{\delta} / S_{T}$ (ratio of the integrated power of the delta rhythm to that of all rhythms). The regression coefficients in this equation were determined by the use of a least square method (Bjorck, 1996) based on the 
data of visual inspection of the standard EEG records by four EEGers

(Nakamura et al., 1985; Nakamura et al., 1992). Based on the criteria of AIC (Akaike Information Criteria) for determining the number of coefficients in a regression model (Akaike, 1977), the combination of the parameters of $\sigma_{\alpha}, S_{\alpha}, S_{\alpha} / S_{T}$ and $S_{\delta} / S_{T}$ was judged to be the best selection out of all possible combinations.

As for the slow waves, the integrated power of delta rhythm, but not of theta rhythm, was incorporated in this linear regression, because inclusion of the integrated power of theta rhythm even deteriorated the agreement of the analysis results with the results of visual inspection (Nakamura et al., 1992).

The quantity of 'asymmetry of the organization' was defined as an absolute value of difference of the organization score between the two sides (Table 2). The quantity of 'frequency' was expressed by the peak frequency $\left(f_{d}\right)$ of the power spectrum parameter. 'Asymmetry' of the frequency was defined as an absolute value of the difference of peak frequency between the two sides (Table 2). Since the quantity of 'amplitude' was defined by the qualified EEGer's as the median voltage of the EEG waves measured peak-to-peak, it was expressed as $10 \sqrt{\bar{S}_{d}}$. 'Asymmetry' of the amplitude was defined as a relative ratio in percentage of the measurement on two sides (Table 2).

For evaluating 'extension' of the posterior dominant rhythm to the anterior region of the head, in order to eliminate the effect of activation of the ear lobe reference electrode by the posterior dominant rhythm, a bipolar derivation was computed from the original referential derivation and subjected to the 
analysis. The 'extension of the posterior dominant rhythm' was represented by the amount of the power within the same dominant frequency band at the fronto-polar to frontal bipolar lead $(\mathrm{Fp}-\mathrm{F})\left(10 \sqrt{S_{d^{\prime}}}\right)$ on each hemisphere (Table 2).

Regarding the beta rhythm, by taking into account the possible presence of the second harmonic of the posterior dominant rhythm, the power in the beta band $\left(S_{\beta}\right)$ was obtained by summing up the power within that band while excluding the amount of $\pm 1 \mathrm{~Hz}$ around twice the peak frequency of the dominant rhythm. The threshold value for the existence of beta rhythm and its asymmetry were given as Equation 3.1 and 3.2, respectively (Table 2). Equation 3.1 was, like Equation1.3, derived from the Markov process amplitude EEG model (Nishida et al., 1986; Bai et al., 2000a).

$$
\begin{aligned}
& 6 \sqrt{\mathrm{S}_{\mathrm{B}}} \geq 10 \mu \mathrm{V} \\
& \left\{\mathrm{S}_{\mathrm{B}}\left(\mathrm{X}_{2}\right)-\mathrm{S}_{\mathrm{B}}\left(\mathrm{X}_{1}\right)\right\} / \max \left\{\mathrm{S}_{\mathrm{B}}\left(\mathrm{X}_{1}\right), \mathrm{S}_{\mathrm{B}}\left(\mathrm{X}_{2}\right)\right\} \times 100
\end{aligned}
$$

The threshold values for the existence of theta rhythm, delta rhythm and the non-dominant alpha rhythm were set as Equation 4.1, 4.2 and 4.3, respectively (Table 2).

$$
\begin{aligned}
& \left(\mathrm{S}_{\theta} / \mathrm{S}_{\mathrm{T}}\right) \times 100 \text { if } 6 \sqrt{\mathrm{S}_{\theta} \geq 15 \mu \mathrm{V}} \\
& \left(\mathrm{S}_{\delta} / \mathrm{S}_{\mathrm{T}}\right) \times 100 \text { if } 6 \sqrt{\mathrm{S}_{6} \geq 25 \mu \mathrm{V}} \\
& \left(\mathrm{S}_{\alpha} / \mathrm{S}_{\mathrm{T}}\right) \times 100 \text { if } 6 \sqrt{\mathrm{S}} \mathrm{S}_{\alpha} \geq 15 \mu \mathrm{V}
\end{aligned}
$$


All these regression coefficients were determined so that the results of automatic analysis could match those of visual inspection by the qualified EEGers as closely as possible by a least square method (Bjorck, 1996).

In the present study, each frequency band was defined as the rhythmic activity of $8 \mathrm{~Hz}$ or more but $13 \mathrm{~Hz}$ or less for the alpha, more than $13 \mathrm{~Hz}$ but less than $25 \mathrm{~Hz}$ for the beta, $4 \mathrm{~Hz}$ or more but less than $8 \mathrm{~Hz}$ for the theta, and less than $4 \mathrm{~Hz}$ for the delta band (Nakamura et al., 1985).

\section{Detection of artifacts}

Automatic detection of artifacts has so far been applied mainly for the polysomnographic recording (Anderer et al., 1999 for review; Klekowicz et al., 2009). Methods for automatically removing artifacts from the EEG record have also been developed (Gao et al., 2010). The present authors developed a system for automatically eliminating the EKG artifacts from EEG which was monopolarly recorded against a non-cephalic reference electrode (Nakamura et al., 1987; 1990). Among different kinds of methods developed for the automatic artifact detection, the methods based on independent component analysis (ICA) have been shown to be useful in various conditions (Anderer et al., 1999 for review; Gao et al., 2010; Grandchamp et al., 2012; Kong et al., 2013).

In the present system of automatic EEG interpretation, artifacts due to blinks, lateral eye movements, EMG, and electrode troubles including that of the ear lobe reference were automatically detected by adopting the strategy which was employed by the qualified EEGers for visually detecting those 
artifacts, and the EEG segments which were found to contain those artifacts were automatically rejected from the final analysis (Fig. 1). Blink artifacts were defined as components within the frequency band of $0.5-4 \mathrm{~Hz}$ which were formed of symmetric positive peaks maximally at the fronto-polar region and which rapidly declined posteriorly (Sugi et al., 1995; Nakamura et al., 1996; Bai et al., 2000b). Artifacts arising from the lateral eye movements were identified when activities of the delta frequency band were detected at bilateral anterior temporal electrodes (F7 and F8) with opposite polarity between the two sides and without any extension to the posterior electrodes (Sugi et al., 1995). Electrode artifact was defined as an activity involving a single electrode without any extension to the adjacent electrodes. Electrode artifact arising from an ear lobe reference was considered when an activity of delta frequency band was present at all electrodes on one hemisphere with the similar waveform and similar amplitude and when there was no similar activity on the opposite hemisphere (Sugi et al., 1995). EMG artifacts were defined as the existence of high frequency activities (35 $50 \mathrm{~Hz}$ ) of the amplitude above $10 \mu \mathrm{V}$ but not higher than the amplitude of beta rhythm in that EEG record (Sugi et al., 1995). All these criteria were established according to the criteria adopted by the qualified EEGers for visual inspection. In the present system, therefore, the annotations made by an EEG technician such as 'eye closure' and 'eye opening', 'artifacts' and 'vigilance level of the subject' were not taken into account.

Other artifacts related to electrodes such as the electrode bridge (Alschuler et al., 2013) and the ground projection have not been taken into account in 
the present study.

It may be possible, however, to incorporate the detection

of these artifacts into the system.

\section{Judgment of subject's vigilance and attention level and selection of appropriate segments}

Vigilance level of the subjects was judged to be decreased when there was a decrease in the amplitude, quantity, frequency and/or organization of the posterior dominant rhythm and when there was an increase of slow waves (Nakamura et al., 1996). In addition, a method for automatically detecting an EEG segment recorded during eyes open was developed by taking into account the above methods for detecting blink artifacts (see Section 5) (Bai et al., 2000b). The EEG segments which were judged to contain the above features of decreased vigilance level or the state of eyes open were excluded from the final analysis (Fig. 1) (Nakamura et al., 1985; 1992; 1996).

As described in Section 2, in some subjects who can maintain a highly attended condition for a short period of time, the posterior dominant rhythm may be completely replaced by the low amplitude beta rhythm during that period. In the automatic interpretation system, therefore, a special caution should be given to avoid misinterpretation of this condition as 'lack of posterior dominant rhythm'. Actually this misinterpretation can be avoided by taking into account the amount of slow waves during that period, because slow waves are expected to increase during the decreased vigilance level or in pathological conditions. In the highly attended condition, by contrast, slow waves are either absent or decreased as compared with the resting 
condition.

In case the patient in question is suspected of being in the state of brain death, all EEG activities including slow waves are expected to be totally absent. Therefore, whenever the results of automatic interpretation suggest 'lack of posterior dominant rhythm', the findings should be carefully confirmed by qualified EEGers on the time series of the EEG data before reaching the final conclusion.

\section{Detection of spikes}

Along with the recent advance in various neuroimaging techniques which are often employed for clinical diagnosis of brain disorders (Shibasaki, 2008 for review), one of the most important purposes for evaluating EEG is to detect the paroxysmal activities, above all the epileptic spikes and spike-and-slow-waves. Therefore, it is of utmost importance to incorporate the spike detection in the automatic EEG interpretation system. A number of methods have already been adopted for the automatic detection of spikes (Gotman and Gloor, 1976; Gotman, 1982, 1985 for review; Frost, 1985 for review; Wilson et al., 1999; Wilson and Emerson 2002 for review; van Putten, 2003; Ji et al., 2011; Olejarczyk et al., 2012; von Ellenrieder et al., 2012; Ayoubian et al., 2013). In this review article, details of the previously reported methods for the automatic spike detection are not introduced, because it is not the main purpose of this paper.

The present authors initially adopted an automatic system for distinguishing a spike signal from the background EEG activities by using a 
morphological filter (Nishida et al., 1999), and recently by determining the threshold values for detecting spikes based on the conditional probability (adaptive spike detection) (Sugi et al., 2002). The system took into account the duration and sharpness of spike, the amplitude of a slow wave immediately following the spike, and the prominence of the slow wave from the background activity (Fig. 3).

Although the present automatic analysis system is still preliminary for accurately detecting all the paroxysmal abnormalities, it was shown that spike detection could be incorporated in the present system as one of its important functions (Fig. 4). However, as an epileptiform discharge varies in morphology during the whole recording session even in the same patient, the sensitivity and specificity for spike detection should be controlled depending on the patient's condition. In this regard, the method of spike detection adopted in the present system of automatic EEG interpretation remains to be further refined. Furthermore, differentiation between the interictal and ictal patterns is an important issue in the field of clinical epileptology, but this is beyond the scope of the present system of automatic EEG interpretation.

\section{Evaluation of the effects of intermittent photic stimulation and hyperventilation}

The present system was also applied to the automatic detection of changes induced in the background activity as a result of intermittent photic stimulation and hyperventilation, and to the automatic detection of 
paroxysmal activities induced by these activation procedures (Fig. 1). As for the intermittent photic stimulation, the present system analyzed any change in the posterior dominant rhythm, the presence or absence of photic evoked potentials to the low stimulus rate and photic driving to the high stimulus rate, asymmetry of those evoked responses, and any paroxysmal abnormalities induced by the stimulation.

Regarding hyperventilation, change in the posterior dominant rhythm, an increase in slow waves and its asymmetry, any paroxysmal abnormalities induced by the procedure, and the duration of the induced slow waves after the end of hyperventilation were automatically analyzed. The results of evaluation of the hyperventilation effect were shown to be in good conformity with those of visual inspection by the qualified EEGers (Zhang et al., 2011). Thus, the automatic analysis of these activation procedures can also be implemented in the automatic interpretation system.

\section{Integrative interpretation of waking EEG and writing its report}

By exploring a computer-assisted system for each step of the above-described procedures and by integrating all of the steps into a consecutive series, the present authors have established an off-line automatic system for making a systematic, quantitative, comprehensive analysis of the adult waking EEG (Nakamura et al., 1992).

The overall flow of the steps taken for the present automatic interpretation system is illustrated in Fig. 1. First, the whole series of 16 channels digital EEG recorded in a referential montage with the ipsilateral 
ear lobe reference is sectioned into consecutive segments of $5 \mathrm{sec}$ long each at all electrodes, and the power spectrum is obtained for all segments. Then the parameters are calculated for all segments and are quantitatively expressed for each frequency component as described in Section 4, and all segments are arranged in the order of organization score of the posterior dominant rhythm. Then, the segments judged to contain artifacts as explained in Section 5 are excluded from the final analysis. Furthermore, the segments in which the subject was judged to be in the decreased vigilance level or in the highly attended condition are also excluded. Of the remaining segments, 10 segments which were judged to be best in the organization of the posterior dominant rhythm were automatically selected and subjected to the final analysis of the background activity and focal or intermittent abnormalities (Fig. 1). In this regard, an attempt to analyze a larger number of EEG segments is currently under way.

In parallel with this main flow of steps, spikes and spike-and-slow-waves are automatically detected from the whole series of the EEG record by the method described in Section 7 (Fig. 3 and Fig. 4). Furthermore, as was described in Section 8, the effects of intermittent photic stimulation and hyperventilation are evaluated in each corresponding part of the EEG. And finally, all results are automatically presented in written form as described below. This procedure is automatically applied from the beginning of the EEG record unless otherwise specified, but it can be started from any point of the EEG record if specified.

For the automatic writing of EEG report, the terminology for describing 
normal as well as abnormal findings for each parameter of each frequency component was newly established by the present authors, so that the results of automatic interpretation appeared in written form in both Japanese and English languages (Appendix A and B) (Nakamura et al., 1993; Nakamura et al., 1996). Recently a group of European investigators proposed a glossary of terminology for the standardized computer-based writing of EEG report (Beniczky et al., 2013). As the terminology proposed by those investigators focused on its application to the epilepsy patients, it was not adopted in the present system.

A written report of EEG in the present system includes an overall judgment of the whole EEG as to whether it is normal or abnormal, and its degree of abnormality if it is abnormal, a systematic list of abnormal findings, the amount and distribution of slow waves if any, the distribution of spikes or spike-and-slow-waves if any, and the results of intermittent photic stimulation and hyperventilation. In addition to the written report, the quantitative data of each parameter for each frequency band are available for each segment of EEG. In view of the fact that an EEGer puts different degrees of weight on each parameter for making the overall judgment of EEG, each parameter was weighted differently as shown in Appendix A. Furthermore, the present EEG report provides comments on the detected artifacts and the information about activation of the ear lobe reference electrode by the posterior dominant rhythm, if any. All these steps are carried out automatically as a single series of continuous procedures, and it takes a few seconds for completing the automatic analysis of an EEG of 
ordinary length.

This automatic analysis system was successfully applied to the adult waking EEG of healthy subjects as well as to patients with various brain disorders (Fig. 5a and 5b, Fig. 6, Table 3 and Table 4)

(Nakamura et al., 1985, 1992, 1993; 1996; Bai et al., 2000a).

The results thus obtained were

generally in good agreement with those obtained through visual inspection of the same record by qualified EEGers both in healthy subjects and in patients with brain disorders including epilepsy patients (Fig. 6) (Nakamura et al., 1992; Nakamura et al., 1996).

\section{Real time evaluation of the technical quality of EEG}

By using a modified version of the present analysis system, it is possible to identify various artifacts and changes in the vigilance level of the subject during the actual data acquisition. The information thus obtained can be provided as a caution for the EEG technicians on a computer display during the actual data acquisition, so that the artifacts and the subject's vigilance level can be controlled during the recording (Fig. 7) (Nakamura et al., 2005). Thus, application of this system will improve the technical quality of EEG records, which is essential for the clinical as well as research purposes.

\section{Discussion}

As a result of a long-standing, continuous, collaborative research by clinical EEGers and system engineers, the present authors have for the first time established a computer-assisted system for automatically interpreting 
the adult waking EEG by taking into account all parameters of all frequency components that constitute the EEG, and the results were successfully presented in written form. This system was aimed at providing the results of automatic interpretation which were in good conformity with the results of visual inspection by qualified EEGers. This system can be used as a supplementary tool for the visual inspection of EEG, and can be also used for educating the EEG trainees and EEG technicians. Upon application of this automatic interpretation system, however, it is of utmost importance to keep in mind that the results of this automatic interpretation can serve only as a supplementary aid for the clinician's diagnostic procedure, and that it never replaces the visual inspection of the qualified EEGers (Nuwer et al., 1999b). This is especially important from a legal/ethical viewpoint.

So far the quantitative EEG analysis has been applied to increase the sensitivity and specificity in the diagnosis of specific disease conditions such as learning and attention disorders in children and adolescents (Chabot et al., 2001) and cognitive disorders in elderly (Prichep et al., 2006). In contrast, the present system of quantitative EEG analysis was developed so that it could be applied to all kinds of brain disorders and not specific for any particular disease condition.

At the initial stage of the present study, the EEG data acquired with an analog electroencephalograph was converted to the digital data before subjecting to a quantitative analysis. After the digital electroencephalograph became available for practical use, the system of automatic interpretation has become more easily applicable because the step 
of analog-digital conversion was spared (Nuwer et al., 1999a for review). At the present time, however, this system of automatic EEG interpretation is not yet applicable to real-time data processing. This is mainly due to the fact that the EEG segments containing various artifacts have to be removed and the appropriate segments have to be selected before making the final quantitative analysis, although all these steps can be automatically conducted within a few seconds as a series of continuous procedures (Fig. 1) (Nakamura et al., 1996).

Two different kinds of data are applicable for testing the usefulness and validity of an automatic EEG interpretation system. One is, like the present system, to establish a system based on the features of visual inspection of each parameter by a limited number of qualified EEGers. This approach is based on the fact that there is a large variability of the threshold values adopted by different EEGers for visual inspection. This system can be compared with the results of visual inspection by another group of EEGers and can be modified according to the features of visual inspection by the second group if needed.

Another way of testing the validity of an automatic EEG interpretation is to subject the results to comparison with the consensus data of visual inspection such as a large computer database as obtained by Aurlien et al.

(2004). The similar method was applied to the data of epilepsy patients (Halford et al., 2013) and to those of the background pattern of norm al as well as abnormal EEGs (Lodder and van Putten, 2013).

Recently Lodder and van Putten made a quantitative analysis of the 
background EEG activity and applied the obtained system to the diagnosis of a number of EEGs (Lodder and van Putten, 2013). They proposed guidelines for describing the background properties of EEG in order to improve the consistency and to reduce the inter-rater variability, and they introduced quantitative algorithms to some key features of the background pattern. In contrast, the present authors took into account all possible properties of the background EEG activities, focal or intermittent abnormalities and paroxysmal abnormalities for enabling an automatic, systematic, integrative, quantitative analysis of the whole series of EEG. These two studies commonly compared the results of the automatic quantitative analysis with the results of visual inspection by qualified EEGers, and both groups obtained relatively good conformity of results between the automatic interpretation and visual inspection.

In view of multiple factors including the use of different EEG instruments and different recording techniques among laboratories, significant inter-rater variability due to different criteria adopted by EEGers and different population of subjects and patients, the concordance of the results between the present system and the EEGer's visual inspection has not been statistically evaluated based on a large number of samples. Instead, data of individual subjects and patients have been reported in a series of papers published by the present authors (Nakamura et al, 1992; 1993;

1996). Another reason for refraining from a large scale statistical study was that the present system was developed based on the threshold values adopted by a limited number of qualified EEGers. In this regard, it is 
important to construct a validation system of the overall judgment of the whole EEG by taking into account the scores of all individual parameters. Once this validation system is established, the inter-rater variability will be evaluated among the laboratories which use the same instrument, the same recording technique and the same diagnostic criteria.

The present study is characterized by its flexibility so that the quantitative representation can be adjusted to the strategy adopted by any individual EEGer for visual inspection. In other words, the threshold values for each parameter could be modified by each EEGer as necessary based on his/her own standard criteria employed for visual inspection. In this regard, however, if a reasonable set of standard quantitative criteria for each EEG parameter becomes available in the future, it may be possible to implement those data into the present system.

In relation to the individuality of the present system, the characteristic features of visual inspection by each individual EEGer can be extracted by the use of an artificial neural network, and those features can be further used to modify the automatic interpretation system if found necessary (Nakamura et al., 1998; 2002).

In the waking EEG of healthy adults, there are some physiological activities which stand out from the time series of the background activity on visual inspection and thus may appear as a special peak in the power spectrum. A typical example is 'slow alpha variant rhythm' which appears mostly at $4-5 \mathrm{~Hz}$ over the posterior region of the head intermixed with the alpha rhythm (Noachtar et al., 1999 for terminology). This activity is 
considered to result from fusion of two successive alpha waves thus obliterating the borderline between the two waves. As another example, 'mu rhythm' appears as an arch-shaped rhythmic activity at $7-11 \mathrm{~Hz}$ over the central or centro-parietal region bilaterally, which remains during the eyes open and is blocked by intended movement of the contralateral hand such as the fist clenching (Noachtar et al., 1999 for terminology). Both 'slow alpha variant rhythm' and 'mu rhythm' are physiologically seen in healthy subjects, and should be distinguished from 'slow posterior dominant rhythm' at the posterior head and rhythmic spikes at the central electrodes, respectively, both of which are clearly abnormal. Since the present system of automatic interpretation does not take into account these two special activities, the system remains to be improved by taking these physiological findings into account. In the present system, if these findings appear as abnormal in the automatic report, the findings should be carefully confirmed by qualified EEGers.

Other physiological activities may appear in the special age groups. A small amount of delta waves can be seen at the posterior region of the head in young adults of age below 25, which are called 'posterior slow waves of youth' and physiological. In the subjects over age 65 , a short run of theta waves may be seen at the temporal electrodes. This is supposed to be also physiological as far as its amount does not exceed $10 \%$ of the total time. In the present system, special criteria were established for two groups of young subjects; one between 15 and 20 years and the other between 20 and 25 years. Furthermore, special criteria were also prepared for two groups of aged 
subjects; one between 65 and 80 years and the other over 80 years. For EEG of children below age 15, special criteria must be developed for each age group by taking into account the developmental change.

The present system may misdiagnose some EEG abnormalities of atypical waveforms such as 'psychomotor variant' and 'phantom spike-and-wave'. Although these terms are discouraged in the IFCN Terminology (Noachtar et al., 1999), the present system may report the former as 'a short run of rhythmic theta waves in the temporal region' and the latter as '6 $\mathrm{Hz}$ spike-and-slow-wave'.

In the future, it is hoped to increase the specificity in detecting epileptic spikes and spike-and-slow-waves, and to add functions to analyze the sleep EEG records, not only to classify the sleep stages but also to detect abnormal activities during sleep. Furthermore, changes of the background activities caused by various procedures during the data acquisition, such as calling attention, talking and opening eyes, might be also automatically analyzed. EEG is becoming increasingly important for the diagnostic aid of neonatal and developmental disorders and infants with brain diseases (Scher, 2004 for review; McCoy and Hahn, 2013). Furthermore, along with an increase in the aged population and with the increasing prevalence of senile brain diseases (Melissant et al., 2005; Buscema et al., 2007; Rossini et al., 2008), further development of the standard criteria for different age groups aiming at the automatic interpretation is warranted. 


\section{References}

Akaike H. A new look at the statistical model identification. IEEE Trans Automat Control 1974;AC-19:716-23.

Alschuler DM, Tenke CE, Bruder GE, Kayser J. Identifying electrode bridging from electrical distance distributions: A survey of publicly-available EEG data using a new method. Clin Neurophysiol 2013; doi: 10.1016/j.clinph.2013.08.024.

Anderer P, Roberts S, Schlogl A, Gruber G, Klosch G, Herrmann W, et al. Artifact processing in computerized analysis of sleep EEG - a review. Neuropsychobiology 1999;40:150-7.

Anderer P, Moreau A, Woertz M, Ross M, Gruber G, Parapatics S, et al. Computer-assisted sleep classification according to the standard of the American Academy of Sleep Medicine: validation study of the AASM version of the Somnolyzer 24 X 7. Neuropsychobiology 2010;62:250-64.

Anderson NR, Doolittle LM. Automated analysis of EEG: opportunities and pitfalls.. J Clin Neurophysiol 2010;27:453-7.

Aurlien H, Gjerde IO, Aarseth JH, Eldoen G, Karlsen B, Skeidsvoll H, et al. EEG background activity described by a large computerized database. Clin Neurophysiol 2004;115:665-673.

Ayoubian L, Lacoma H, Gotman J. Automatic seizure detection in SEEG using high frequency activities in wavelet domain. Med Eng Phys 2013; 35:319-28.

Bai O, Nakamura M, Ikeda A, Shibasaki H. Nonlinear Markov process amplitude EEG model for nonlinear coupling interaction of spontaneous EEG. IEEE Trans Biomed Eng 2000a;47:1141-6.

Bai O, Nakamura M, Ikeda A, Shibasaki H. Automatic detection of open and closed 
eye states in the electroencephalographic (EEG) record for background EEG interpretation by the trigger method. Frontiers Med Biol Eng 2000b;10:1-15. Beniczky S, Aurlien H, Brogger JC, Fuglsang-Frederiksen A, Martins-da-Silva A, Trinka E, et al. Standardized computer-based organized reporting of EEG: SCORE. Epilepsia 2013;54:1112-24.

Bjorck A. Numerical Methods for Least Square Problems. SIAM, Philadelphia, 1996, pp. 1-36.

Brignol A, Al-ani T, Drouot X. Phase space and power spectral approaches for EEG-based automatic sleep-wake classification in humans: A comparative study using short and standard epoch lengths. Comp Method Programs Biomed 2013;109:227-38.

Buscema M, Rossini P, Babiloni C, Grossi E. The IFAST model, a novel parallel nonlinear EEG analysis technique, distinguishes mild cognitive impairment and Alzheimer's disease patients with high degree of accuracy. Artif Intell Med 2007;40:127-41.

Caso F, Cursi M, Magnani G, Fanelli G, Falautano M, Comi G, et al. Quantitative EEG and LORETA: valuable tools in discerning FTD from AD? Neurobiol Aging 2012;33:2343-56.

Chabot RJ, di Michele F, Prichep L, John ER. The clinical role of computerized EEG in the evaluation and treatment of learning and attention disorders in children and adolescents. J Neuropsychiatry Clin Neurosci 2001;13:171-86.

Claassen J, Hirsch LJ, Kreiter KT, Du EY, Connolly ES, Emerson RG, et al. Quantitative continuous EEG for detecting delayed cerebral ischemia in patients with poor grade subarachnoid haemorrhage. Clin Neurophysiol 
2004;115:2699-710.

Cloostermans MC, de Vos CC, van Putten MJ. A novel approach for computer assisted EEG monitoring in the adult ICU. Clin Neurophysiol 2011;122:2100-9.

Cooly JW, Tukey JW. An algorithm for the machine computation of complex Fourier series. Math Computation 1965;19:297-301.

da Rosa AC, Paiva T. Automatic detection of K-complexes: validation in normals and dysthymic patients. Sleep 1993;16:239-48.

Finnigan SP, Rose SE, Walsh M, Griffin M, Janke AL, McMahon KL, et al. Correlation of quantitative EEG in acute stroke with 30 days NIHSS score: comparison with diffusion and perfusion MRI. Stroke 2004;35:899-903.

Finnigan SP, Walsh M, Rose SE, Chalk JB. Quantitative EEG indices of sub-acute ischaemic stroke correlate with clinical outcomes. Clin Neurophysiol 2007;118:2525-32.

Finnigan S, van Putten MJAM. EEG in ischaemic stroke: Quantitative EEG can uniquely inform (sub-)acute prognosis and clinical management. Clin Neurophysiol 2013;124:10-19.

Frost Jr JD. Automatic recognition and characterization of epileptiform discharges in the human EEG. J Clin Neurophysiol 1985;2:231-49.

Gao J, Yang Y, Sun J, Yu G. Automatic removal of various artifacts from EEG signals using combined methods. J Clin Neurophysiol 2010;27:312-20.

Gotman J, Gloor P. Automatic recognition and quantification of interictal epileptic activity in the human scalp EEG. Electroencephalogr Clin Neurophysiol 1976;41:513-29. 
Gotman J. Automatic recognition of epileptic seizures in the EEG.

Electroencephalogr Clin Neurophysiol 1982;54:530-40.

Gotman J. Practical use of computer-assisted EEG interpretation in epilepsy. J Clin Neurophysiol 1985;2:251-65.

Halford JJ, Schalkoff RJ, Zhou J, Benbadis SR, Tatum WO, Turner RP, et al. Standardized database development for EEG epileptiform transient detection: EEGnet scoring system and machine learning analysis. J Neurosci Methods 2013;212:308-16.

Hamming RW. Digital Filters. Prentice-Hall Inc., 1989, pp. 37-41.

Hirsch LJ, LaRoche SM, Gaspard N, Gerard E, Svoronos A, et al. American Clinical Neurophysiology Society's standardized critical care EEG terminology: 2012 version. J Clin Neurophysiol 2013;30:1-27.

Inoue K, Kumamaru K, Sagara S, Matsuoka S. Pattern recognition approach to human sleep EEG analysis and detection of sleep stages. Mem Fac Eng Kyushu Univ 1982;42:177-95.

Jensen PS, Sorensen HBD, Leonthin HL, Jennum P. Automatic sleep scoring in normals and in individuals with neurodegenerative disorders according to new international sleep scoring criteria. J Clin Neurophysiol 2010;27:296-302.

Ji Z, Sugi T, Goto S, Wang X, Ikeda A, Nagamine T, et al. An automatic spike detection system based on elimination of false positives using the large-area context in the scalp EEG. IEEE Trans Biomed Eng 2011;58:2478-88.

Jobert M, Escola H, Poiseau E, Gaillard P. Automatic analysis of sleep using two parameters based on principal component analysis of electroencephalography spectral data. Biol Cybern 1994;71:197-207. 
Kim JS, Lee SH, Park G, Kim S, Bae SM, Kim DW, et al. Clinical implications of quantitative electroencephalography and current source density in patients with Alzheimer's disease. Brain Topogr 2012;25:461-74.

Klekowicz H, Malinowska U, Piotrowska AJ, Wolynczyk-Gmaj D, Niemcewicz S, Durka PJ. On the robust parametric detection of EEG artifacts in polysomnographic recordings. Neuroinform 2009;7:147-60.

Leuchter AF, Cook IA, Hunter AM, Cai C, Horvath S. Resting-state quantitative electroencephalography reveals increased neurophysiologic connectivity in depression. PLoS One 2012; 7:e32508.

Lodder SS, van Putten MJAM. Automated EEG analysis: Characterizing the posterior dominant rhythm. J Neurosci Methods 2011;200:86-93.

Lodder SS, van Putten MJAM. Quantification of the adult EEG background pattern. Clin Neurophysiol 2013;124:228-37.

Marcuse LV, Schneider M, Mortati KA, Donnelly KM, Arnedo V, Grant AC. Quantitative analysis of the EEG posterior-dominant rhythm in healthy adolescents. Clin Neurophysiol 2008;119:1778-81.

Mathewson KJ, Jetha MK, Drmic IE, Bryson SE, Goldberg JO, Schmidt LA. Regional EEG alpha power, coherence, and behavioral symptomatology in autism spectrum disorder. Clin Neurophysiol 2012;123:1798-809.

Matsuoka S, Arakaki Y, Numaguchi K, Ueno S. The effect of dexamethasone on electroencephalograms in patients with brain tumors. With specific reference to topographic computer display of delta activity. J Neurosurg 1978;48:601-8.

McCoy B, Hahn CD. Continuous EEG monitoring in the neonatal intensive care unit. J Clin Neurophysiol 2013;30:106-14. 
Melissant C, Ypma A. Frietman EEE, Stam CJ. A method for detection of Alzheimer's disease using ICA-enhanced EEG measurements. Artif Intell Med 2005;33:209-22.

Nagata K. Topographic EEG Mapping in cerebrovascular disease. Brain Topogr 1989;2:119-28.

Nakamura M, Nishida S, Neshige R, Shibasaki H. Quantitative analysis of 'organization' by feature extraction of the EEG power spectrum.

Electroencephalogr Clin Neurophysiol 1985, 60:84-9.

Nakamura M, Shibasaki H. Elimination of EKG artifacts from EEG records; a new method of non-cephalic referential EEG recording. Electroencephalogr Clin Neurophysiol 1987;66:89-92.

Nakamura M, Shibasaki H, Nishida S. Method for recording short latency evoked potentials using an EKG artifact elimination procedure. J Biomed Eng 1990;12:51-6.

Nakamura M, Shibasaki H, Imajoh K, Nishida S, Neshiga R, Ikeda A. Automatic EEG interpretation: a new computer-assisted system for the automatic integrative interpretation of awake background EEG. Electroencephalogr Clin Neurophysiol 1992, 82:423-31.

Nakamura M, Shibasaki H, Imajoh K, Ikeda A, Kakigi R. Automatic EEG report making for awake background EEG. Jap J Clin Neurophysiol 1993;21:47-56 (abstract in English).

Nakamura M, Sugi T, Ikeda A, Kakigi R, Shibasaki H. Clinical application of automatic integrative interpretation of awake background EEG: quantitative interpretation, report making, and detection of artifacts and reduced vigilance 
level. Electroencephalogr Clin Neurophysiol 1996, 98:103-12.

Nakamura M, Sugi T, Ikeda A, Shibasaki H. Realization of artificial intelligence for integrative electroencephalogram interpretation. Artif Life Robotics 1998;2:91-5.

Nakamura M, Sugi T, Ikeda A, Shibasaki H. Automatic EEG interpretation adaptable to individual electroencephalograher using artificial neural network. Int J Adapt Control Signal Process 2002;16:25-37.

Nakamura M, Chen Q, Sugi T, Ikeda A, Shibasaki H. Technical quality evaluation of EEG recording based on electroencephalographers' knowledge. Med Eng Phys 2005;27:93-100.

Nishida S, Nakamura M, Shibasaki H. An EEG model expressed by the sinusoidal waves with the Markov process amplitude. JJME 1986;24:8-14. (abstract in English)

Nishida S, Nakamura M, Ikeda A, Shibasaki H. Signal separation of background EEG and spike by using morphological filter. Med Eng Phys 1999;21:601-8.

Noachtar S, Binnie C, Ebersole J, Mauguiere F, Sakamoto A, Westmoreland B. A glossary of terms most commonly used by clinical electroencephalographers and proposal for the report form for the EEG findings. In: Deuschl G, Eisen A (Eds). Recommendations for the Practice of Clinical Neurophysiology: Guidelines of the International Federation of Clinical Neurophysiology, Electroencephalogr Clin Neurophysiol Suppl. 52, 1999, pp. 21-40.

Nuwer MR, Jordan SE, Ahn SS. Evaluation of stroke using EEG frequency analysis and topographic mapping. Neurology 1987;37:1153-9.

Nuwer MR, Comi G, Emerson E, Fuglsang-Frederiksen A, Guerit J-M, Hinrichs H, et al. IFCN standards for digital recording of clinical EEG. 
In: Deuschl G, Eisen A (Eds). Recommendations for the Practice of Clinical

Neurophysiology: Guidelines of the International Federation of Clinical

Neurophysiology, Electroencephalogr Clin Neurophysiol Suppl. 52, 1999a, pp.

11-14.

Nuwer MR, Lehmann D, Lopes da Silva F, Matsuoka S, Sutherling W, Vibert JF.

IFCN guidelines for topographic and frequency analysis of EEGs and EPs. In:

Deuschl G, Eisen A (Eds). Recommendations for the Practice of Clinical

Neurophysiology: Guidelines of the International Federation of Clinical

Neurophysiology, Electroencephalogr Clin Neurophysiol Suppl. 52, 1999b, pp.

$15-20$.

Nuwer MR, Hovda DA, Schrader LM, Vespa PM. Routine and quantitative EEG in mild traumatic brain injury. Clin Neurophysiol 2005;116:2001-25.

Olejarczyk E, Jozwik A, Zmyslowski W, Sobieszek A. Automatic detection and analysis of the EEG Sharp Wave-Slow Wave patterns evoked by fluorinated inhalation anesthetics. Clin Neurophysiol 2012;123:1512-1522.

Prichep LS, John ER, Ferris SH, Rausch L, Zang Z, Cancro R, et al. Prediction of longitudinal cognitive decline in normal elderly with subjective complaints using electrophysiological imaging. Neurobiol Aging 2006;27:471-81.

Ronzhina M, Janou_O, Kolá_rová J, Nováková M, Honzík P, Provazník I.

Sleep scoring using artificial neural networks. Sleep Med Rev 2012;16:251-263.

Rossini PM, Buscema M, Capriotti M, Grossi E, Rodriguez G, Del Percio C, et al. Is it possible to automatically distinguish resting EEG data of normal elderly vs. mild cognitive impairment subjects with high degree of accuracy? Clin Neurophysiol 2008;119:1534-45. 
Scher MS. Automated EEG-sleep analyses and neonatal neurointensive care. Sleep Med 2004;5:533-40.

Sheorajpanday RV, Nagels G, Weeren AJ, van Putten MJ, De Deyn PP.

Reproducibility and clinical relevance of quantitative EEG parameters in cerebral ischemia: a basic approach. Clin Neurophysiol 2009;120:845-55.

Sheorajpanday RV, Nagels G, Weeren AJ, van Putten MJ, De Deyn PP.

Quantitative EEG in ischemic stroke: correlation with functional status after 6 months. Clin Neurophysiol 2011;122:874-83.

Shibasaki H. Human brain mapping: Hemodynamic response and electrophysiology.

Clin Neurophysiol 2008;119:731-43.

Strungaru C, Popescu MS. Neural network for sleep EEG K-complex detection.

Biomed Tech 1998;43 (Suppl 3):113-6.

Sugi T, Nakamura M, Ikeda A, Kakigi R, Shibasaki H. Automatic detection of artifacts for pre-processing of automatic EEG interpretation. JJME 1995;33:203-13 (abstract in English).

Sugi T, Nakamura M, Ikeda A, Shibasaki H. Adaptive EEG spike detection: determination of threshold values based on conditional probability. Frontiers med Biol Eng 2002;11:261-77.

van Putten MJAM. Nearest neighbor phase synchronization as a measure to detect seizure activity from scalp EEG recordings. J Clin Neurophysiol 2003;20:320-5. van Putten MJAM, Peters JM, Mulder SM, de Haas JAM, Bruijninckx CMA, Tavy DLJ. A brain symmetry index (BSI) for online EEG monitoring in carotid endarterectomy. Clin Neurophysiol 2004a;115:1189-94.

van Putten MJAM, Tavy DLJ. Continuous quantitative EEG monitoring in 
hemispheric stroke patients using the brain symmetry index. Stroke 2004b;35:2489-92.

von Ellenrieder N, Andrade-Valença LP, Dubeau F, Gotman J. Automatic detection of fast oscillations $(40-200 \mathrm{~Hz})$ in scalp EEG recordings. Clin Neurophysiol 2012;123:670-80.

Wilson SB, Turner CA, Emerson RG, Scheuer ML. Spike detection II: automatic, perception-based detection and clustering. Clin Neurophysiol 1999;110:404-11.

Wilson SB, Emerson R. Spike detection: a review and comparison of algorithms. Clin Neurophysiol 2002;113:1873-81.

Zhang X, Wang X, Sugi T, Ikeda A, Nagamine T, Shibasaki H, et al. Automatic interpretation of hyperventilation-induced electroencephalogram constructed in the way of qualified electroencephalographer's visual inspection. Med Biol Eng Comput 2011;49:171-80. 


\section{Figure Legends}

Figure 1. A flow of steps taken for the present automatic EEG interpretation system. First the whole series of digital EEG is sectioned into the consecutive segments of $5 \mathrm{sec}$ long each, and the power spectrum is obtained for each segment. Then the parameters are calculated and quantitatively expressed for each frequency component, and all segments are arranged in the order of organization score. After the segments found to contain artifacts and those found to be in the state of drowsiness or highly attended condition of the subject are removed, 10 most appropriate segments are selected and subjected to the final analysis of the background activity and focal or intermittent abnormalities. In parallel with this main flow, spikes and spike-and-slow-waves are automatically detected from the whole series of an EEG record, and the effects of intermittent photic stimulation and hyperventilation are evaluated in each corresponding part of the EEG. Quantitative data thus obtained are then translated into a language by using the terminology proposed by the authors (Appendix A and B), and the report is automatically presented in written form.

Figure 2. The time series of a $5 \mathrm{~s}$ segment of $16^{-c h a n n e l ~ E E G ~ r e c o r d e d ~ i n ~ a ~}$ referential montage (left panel) and the power spectrùm calculated from the time series (right panel). The data were obtained from a 29-year-old patient with left temporal lobe epilepsy who was taking a large dose of 
carbamazepine after the surgical treatment of the epileptogenic focus. This EEG segment shows 'slow alpha rhythm' which might be due to the medication.

Figure 3. Criteria adopted for detecting spikes in the present system of automatic EEG interpretation. Amplitude of the peak of a surface-negative spike measured from the preceding positive peak and to the following positive peak is represented by $A_{S 1}$ and $A_{S 2}$, respectively. Duration of the negative spike measured from the preceding positive peak and to the following positive peak is represented by $D_{S 1}$ and $D_{S 2}$, respectively. Thus, the sharpness of spike is represented by $A_{S 1} / D_{S 1}$ and $A_{S 2} / D_{S 2}$. Amplitude of a slow wave following the spike is represented by $A_{W}$. Prominence of the slow wave from the background activity is represented by $A_{W} / A_{T}$ where $A_{T}$ is the mean amplitude of the whole background activities in all frequency bands computed for each EEG segment. (Modified from Sugi et al., 2002 with permission.)

Figure 4. An example of the automatic detection of spikes in a 26-year-old patient with clinical diagnosis of temporal lobe epilepsy. The time series of EEG is shown on the left panel, and the results of quantitative analysis are shown in the table on the left upper corner of the right panel, and the topographic information of each frequency band of the background EEG is presented on the right upper corner of the right panel. The scalp distribution of the spike thus detected is shown on the bottom of the right 
panel.

Figure 5. Examples of 3 segments out of the 10 selected EEG segments subjected to the automatic analysis (a) and topographic illustration of slow waves thus detected (b) from a 40-year-old patient with temporal lobe epilepsy. In (a), segment 1 contains a blink artifact and segment 5 contains a short episode of rhythmic theta waves of moderate amplitude on the midline fronto-central region. Table 3 shows the results of quantitative analysis of the same record, and Table 4 shows the written report obtained by automatic analysis of the same data.

Figure 6. Results of automatic interpretation of an EEG in comparison with those of visual inspection of the same record by a qualified EEGer. The patient was 46 years old with bilateral temporal lobe epilepsy following acute encephalitis in childhood. The time series of EEG contains high amplitude epileptic spike-and-slow-waves over the right hemisphere. There is a good agreement between the two sets of reports.

Figure 7. Diagram illustrating a flow of methods employed for the real time evaluation of the quality of EEG recording. (Modified from Nakamura et al., 2005 with permission.) 
Appendix A. Terminology used in the present system for automatically writing the EEG report

\begin{tabular}{|c|c|c|c|c|}
\hline No. & Items & Sc. & Terminology & Weight \\
\hline \multicolumn{5}{|c|}{ Posterior dominant rhythm } \\
\hline 1 & Existence & 3 & lack of dominant rhythm & 10.0 \\
\hline 2 & Organization & $\begin{array}{l}3 \\
2 \\
1\end{array}$ & $\begin{array}{l}\text { markedly disorganized } \\
\text { disorganized } \\
\text { poorly organized }\end{array}$ & $\begin{array}{l}7.0 \\
4.5 \\
2.0\end{array}$ \\
\hline 3 & Asymmetry & $\begin{array}{l}3 \\
2 \\
1\end{array}$ & $\begin{array}{l}\text { marked asymmetry of dominant rhythm organization, poor on }(\mathrm{L}, \mathrm{R}) \\
\text { asymmetry of dominant rhythm organization, poor on }(\mathrm{L}, \mathrm{R}) \\
\text { slight asymmetry of dominant rhythm organization, poor on }(\mathrm{L}, \mathrm{R})\end{array}$ & $\begin{array}{l}5.0 \\
3.5 \\
2.0\end{array}$ \\
\hline 4 & Frequency & $\begin{array}{l}3 \\
2 \\
1\end{array}$ & $\begin{array}{l}\text { markedly slow dominant rhythm }(\mathrm{Hz}) \\
\text { slow dominant rhythm }(\mathrm{Hz}) \\
\text { slow alpha rhythm }\end{array}$ & $\begin{array}{l}8.0 \\
5.0 \\
2.0\end{array}$ \\
\hline 5 & Asymmetry & $\begin{array}{l}3 \\
2 \\
1\end{array}$ & $\begin{array}{l}\text { marked asymmetry of dominant rhythm frequency, slower on }(\mathrm{L}, \mathrm{R}) \\
\text { asymmetry of dominant rhythm frequency, slower on }(\mathrm{L}, \mathrm{R}) \\
\text { slight asymmetry of dominant rhythm frequency, slower on }(\mathrm{L}, \mathrm{R})\end{array}$ & $\begin{array}{l}5.0 \\
3.5 \\
2.0\end{array}$ \\
\hline 6 & Amplitude & $\begin{array}{l}2 \\
1 \\
\end{array}$ & $\begin{array}{l}\text { excessively high amplitude dominant rhythm } \\
\text { high amplitude dominant rhythm }\end{array}$ & $\begin{array}{l}3.0 \\
2.0\end{array}$ \\
\hline 7 & Asymmetry & $\begin{array}{l}3 \\
2 \\
1\end{array}$ & $\begin{array}{l}\text { suppression of dominant rhythm on }(\mathrm{L}, \mathrm{R}) \\
\text { depression of dominant rhythm on }(\mathrm{L}, \mathrm{R}) \\
\text { mild depression of dominant rhythm on }(\mathrm{L}, \mathrm{R})\end{array}$ & $\begin{array}{l}5.0 \\
3.5 \\
2.0\end{array}$ \\
\hline 8 & Extension & $\begin{array}{l}3 \\
2 \\
1\end{array}$ & $\begin{array}{l}\text { excessive anterior extension of alpha rhythm } \\
\text { anterior extension of alpha rhythm } \\
\text { mild anterior extension of alpha rhythm }\end{array}$ & $\begin{array}{l}2.0 \\
1.5 \\
1.0\end{array}$ \\
\hline \multicolumn{5}{|c|}{ Beta rhythm } \\
\hline 9 & Amplitude & $\begin{array}{l}2 \\
1 \\
\end{array}$ & $\begin{array}{l}\text { excessively high amplitude rhythmic fast activity } \\
\text { high amplitude rhythmic fast activity }\end{array}$ & $\begin{array}{l}3.0 \\
2.0\end{array}$ \\
\hline 10 & Asymmetry & $\begin{array}{l}3 \\
2 \\
1\end{array}$ & $\begin{array}{l}\text { suppression of rhythmic fast activity on }(\mathrm{L}, \mathrm{R}) \\
\text { depression of rhythmic fast activity on }(\mathrm{L}, \mathrm{R}) \\
\text { mild depression of rhythmic fast activity on }(\mathrm{L}, \mathrm{R})\end{array}$ & $\begin{array}{l}5.0 \\
3.5 \\
2.0\end{array}$ \\
\hline \multicolumn{5}{|c|}{ Theta rhythm } \\
\hline 11 & Duration & $\begin{array}{l}3 \\
2 \\
1\end{array}$ & $\begin{array}{l}\text { continuous, rhythmic and/or irregular theta waves } \\
\text { intermittent, rhythmic and/or irregular theta waves } \\
\text { occasional theta waves }\end{array}$ & $\begin{array}{l}8.0 \\
5.0 \\
2.0\end{array}$ \\
\hline 12 & Electrodes & & & \\
\hline \multicolumn{5}{|c|}{ Delta rhythm } \\
\hline 13 & Duration & $\begin{array}{l}3 \\
2 \\
1 \\
\end{array}$ & $\begin{array}{l}\text { continuous, rhythmic and/or irregular delta waves } \\
\text { intermittent, rhythmic and/or irregular delta waves } \\
\text { occasional delta waves }\end{array}$ & $\begin{array}{l}8.0 \\
5.0 \\
2.0\end{array}$ \\
\hline 14 & Electrodes & & & \\
\hline \multicolumn{5}{|c|}{ Non-dominant alpha rhythm } \\
\hline 15 & Duration & $\begin{array}{l}3 \\
2 \\
1\end{array}$ & $\begin{array}{l}\text { continuous non-dominant alpha frequency } \\
\text { intermittent non-dominant alpha frequency } \\
\text { occasional non-dominant alpha frequency }\end{array}$ & $\begin{array}{l}4.0 \\
3.0 \\
2.0\end{array}$ \\
\hline 16 & Electrodes & & & \\
\hline
\end{tabular}

Modified from Nakamura et al., 1993 with permission. 
Appendix B. Terminology used in the present system for automatically describing the scalp distribution of normal as well as abnormal activities

\begin{tabular}{|c|c|c|}
\hline Region & Electrodes & Terminology \\
\hline R1 & $12 \leq($ total $)$ & diffusely \\
\hline $\mathrm{R} 2$ & $6 \leq($ left $),($ total $) \leq 11$ & more on the left hemisphere \\
\hline R3 & $6 \leq($ right $),($ total $) \leq 11$ & more on the right hemisphere \\
\hline R4 & $6 \leq(\mathrm{Fp}, \mathrm{F}>\mathrm{C}, \mathrm{T} 3, \mathrm{~T} 4)$, symmetry & bianteriorly \\
\hline R5 & $6 \leq(\mathrm{Fp}, \mathrm{F}>\mathrm{C}, \mathrm{T} 3, \mathrm{~T} 4)$ & anteriorly \\
\hline R6 & $6 \leq(\mathrm{O}, \mathrm{P}>\mathrm{T}, \mathrm{C})$ & posteriorly \\
\hline R7 & $5 \leq(\mathrm{C}, \mathrm{F})$ & on the fronto-central region \\
\hline $\mathrm{R} 8$ & $4 \leq(\mathrm{Fp} 1, \mathrm{~F} 3, \mathrm{~F} 7>\mathrm{C} 3, \mathrm{~T} 3)$ & on the left anterior quadrant \\
\hline R9 & $4 \leq(\mathrm{Fp} 2, \mathrm{~F} 4, \mathrm{~F} 8>\mathrm{C} 4, \mathrm{~T} 4)$ & on the right anterior quadrant \\
\hline $\mathrm{R} 10$ & $3 \leq(\mathrm{O} 1, \mathrm{P} 3, \mathrm{~T} 5>\mathrm{C} 3, \mathrm{~T} 3)$ & on the left posterior quadrant \\
\hline R11 & $3 \leq(\mathrm{O} 2, \mathrm{P} 4, \mathrm{~T} 6>\mathrm{C} 4, \mathrm{~T} 4)$ & on the right posterior quadrant \\
\hline $\mathrm{R} 12$ & $2 \leq(\mathrm{C}, \mathrm{P})$ & on the centro-parietal region \\
\hline $\mathrm{R} 13$ & $2 \leq(\mathrm{Fp} 1, \mathrm{~F} 3, \mathrm{~F} 7)$ & on the left frontal region \\
\hline R14 & $2 \leq(\mathrm{Fp} 2, \mathrm{~F} 4, \mathrm{~F} 8)$ & on the right frontal region \\
\hline R15 & $2 \leq(\mathrm{F})$ & on the frontal region \\
\hline
\end{tabular}

R1 - R15 of Region: categories of scalp distribution 
Modified from Nakamura et al., 1993 with permission. 


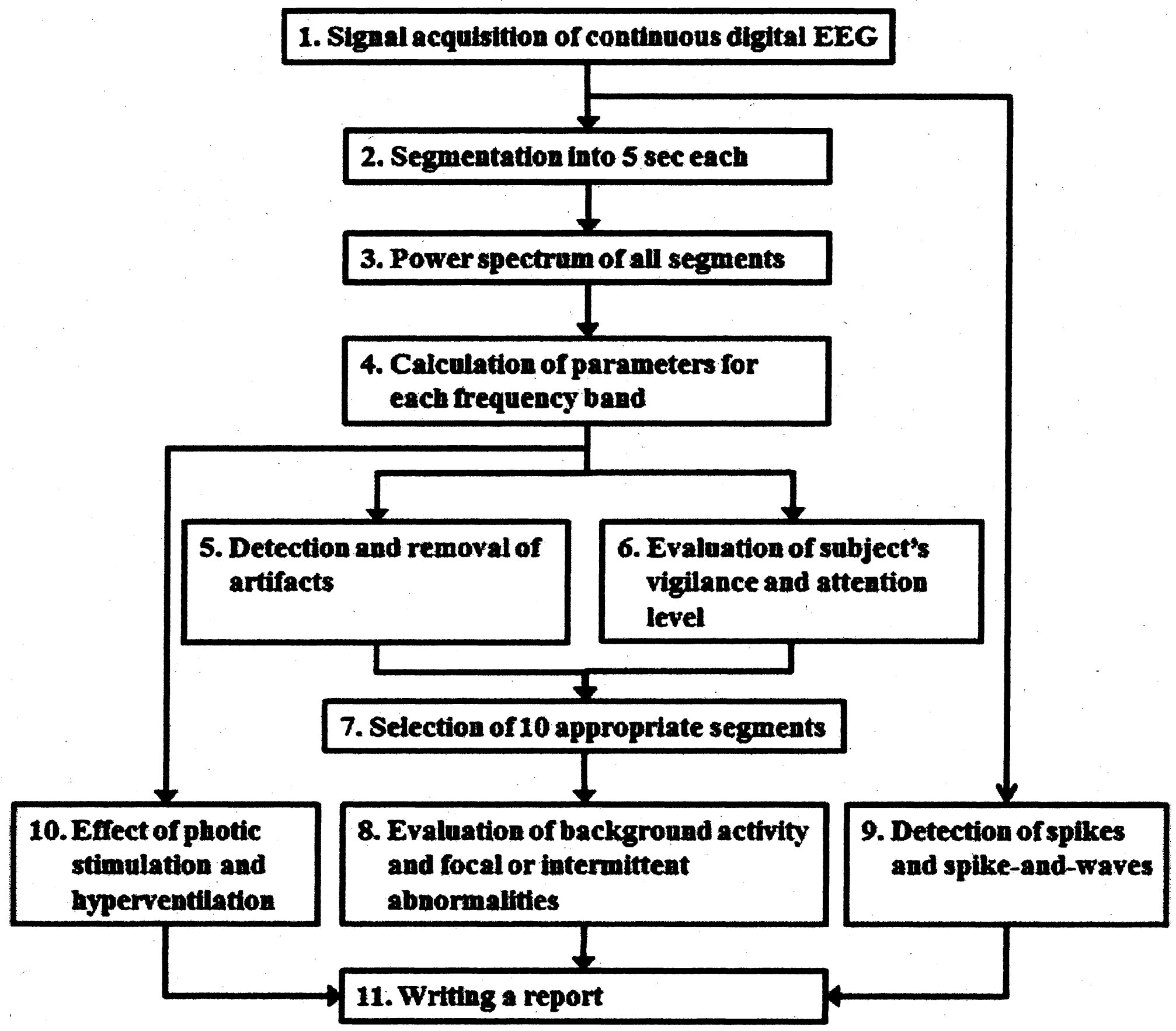




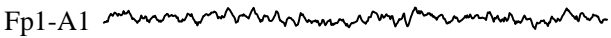

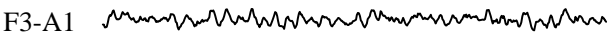

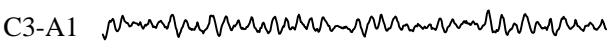

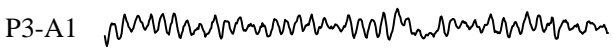

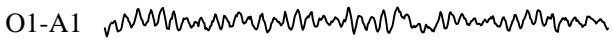

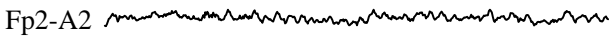

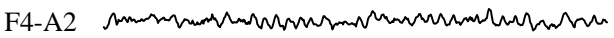

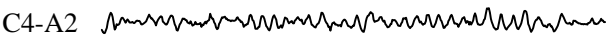

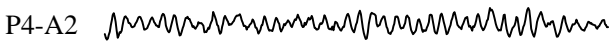

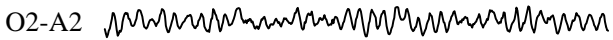

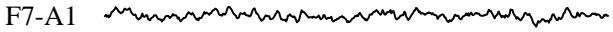

T3-A1 201m

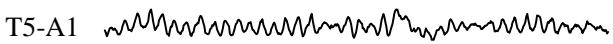
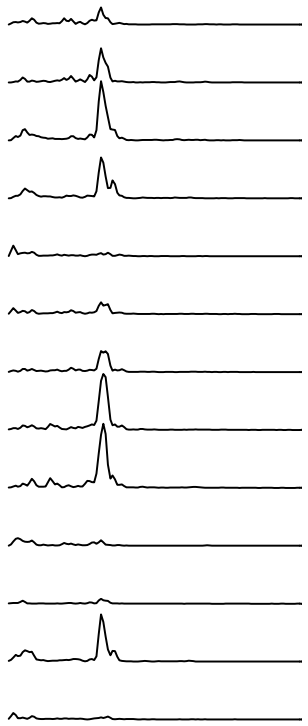

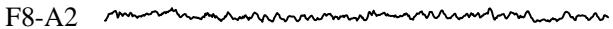

T4-A2

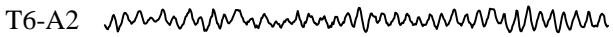

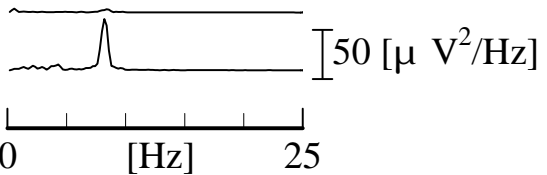
$100 \mu \mathrm{V}$ 


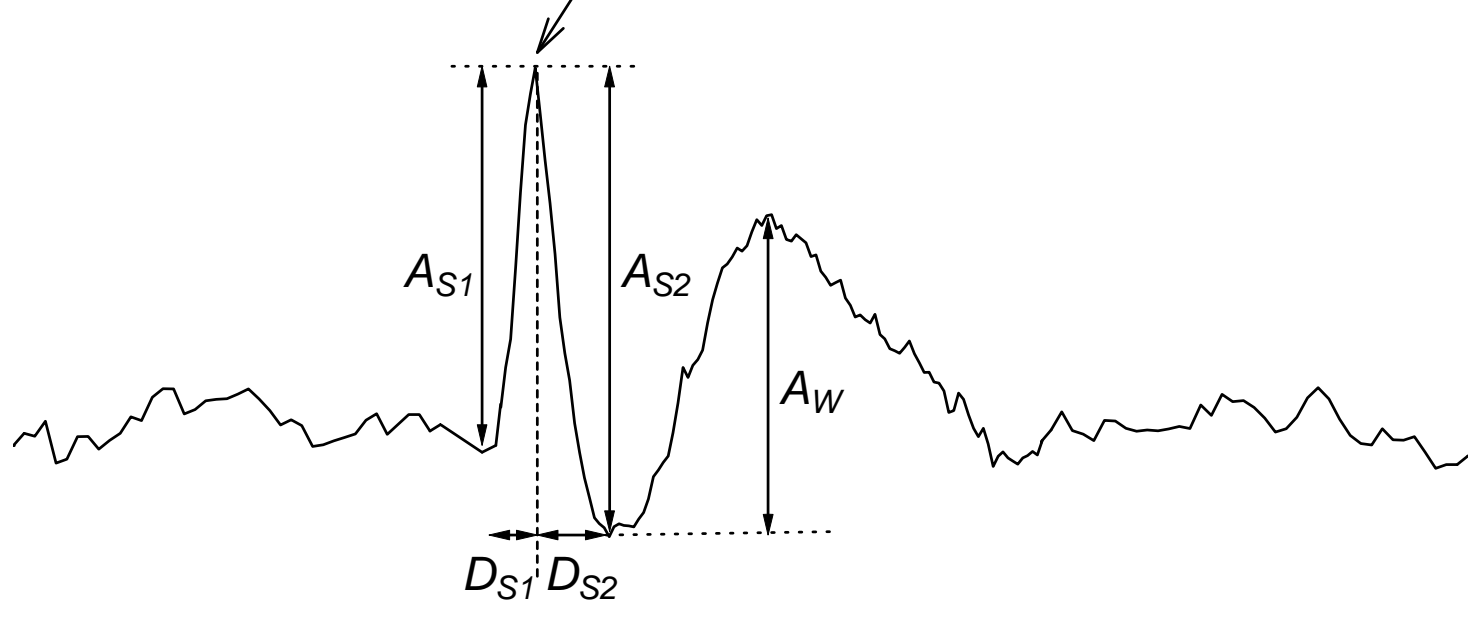




\section{$\mathbf{F}$ :}

Fp1-A1 1 manty

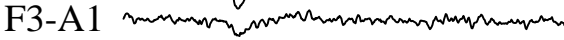

C3-A1

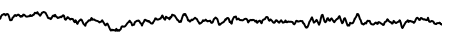

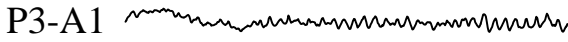

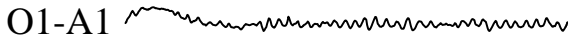

Fp2-A2 mmormy

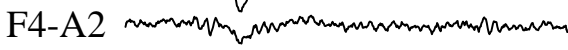

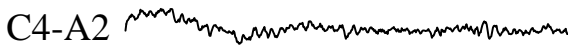

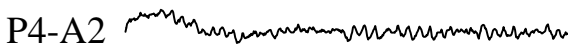

O2-A2

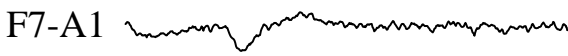

T3-A1

T5-A1

F8-A2

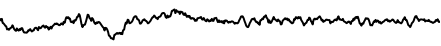

T4-A2

T6-A2
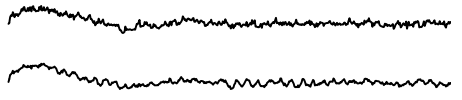

$1 \mathrm{~s}$ $100 \mu \mathrm{V}$

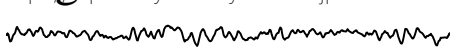

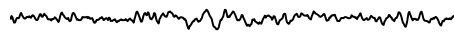

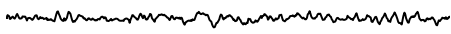

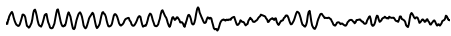

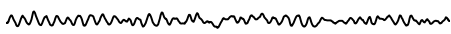

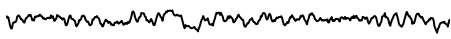

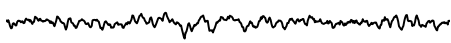

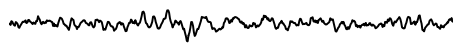

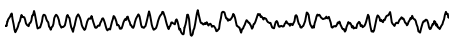

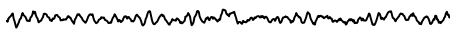

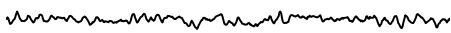

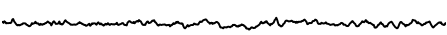

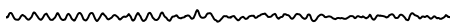

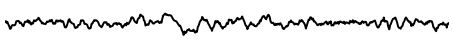

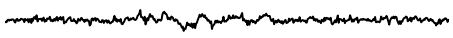

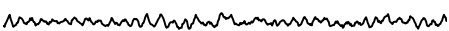

Segment 6 KURENAI 紅

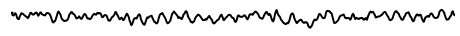

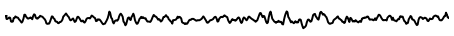

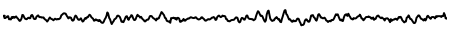

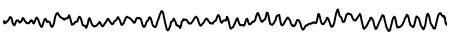

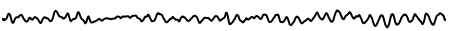

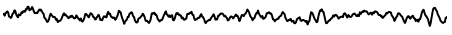

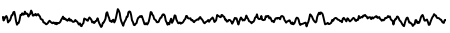

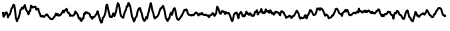

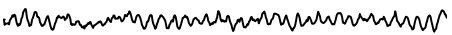

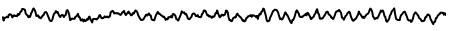

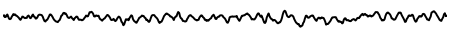

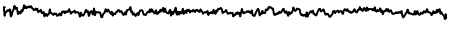

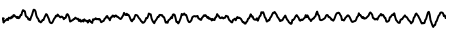




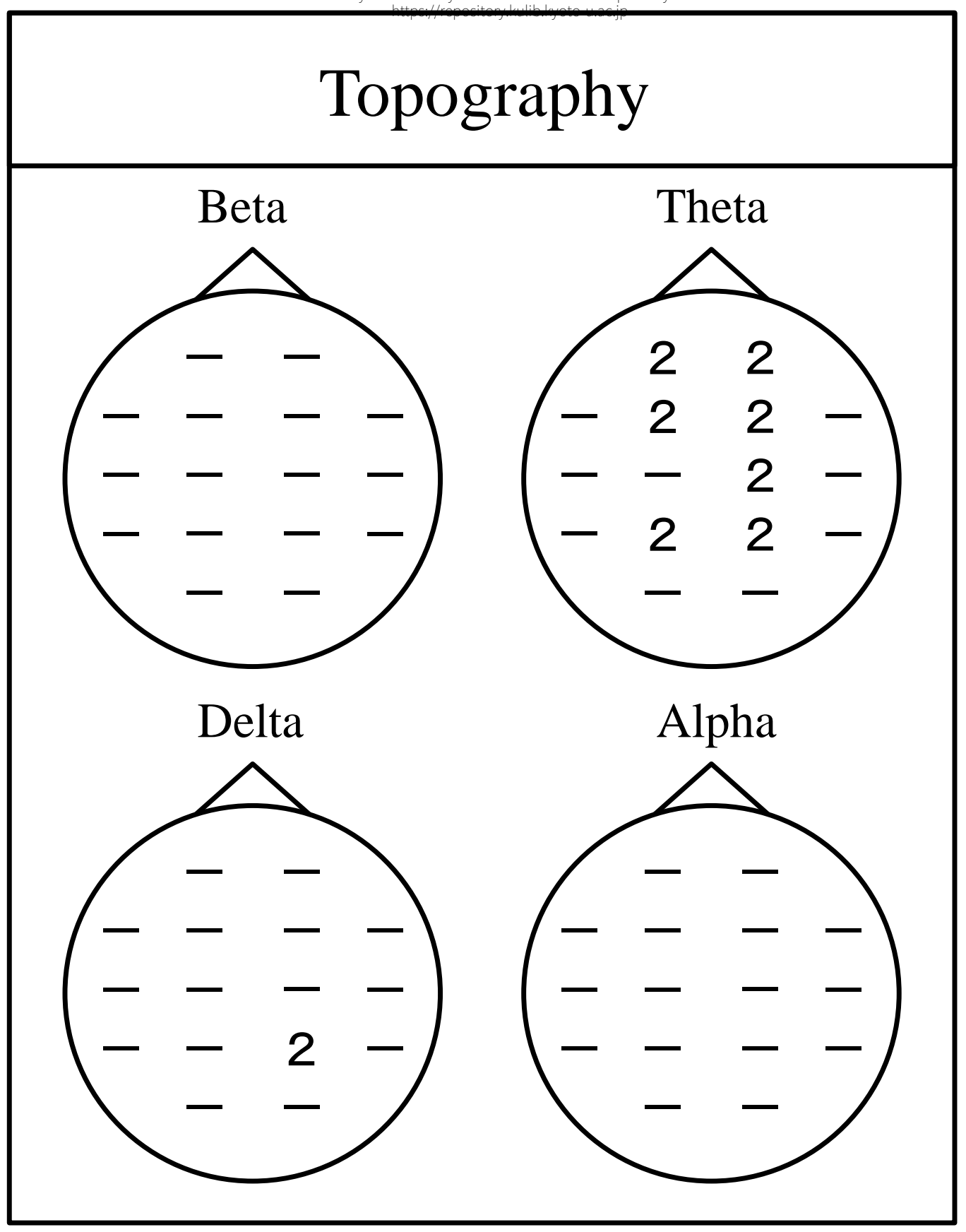




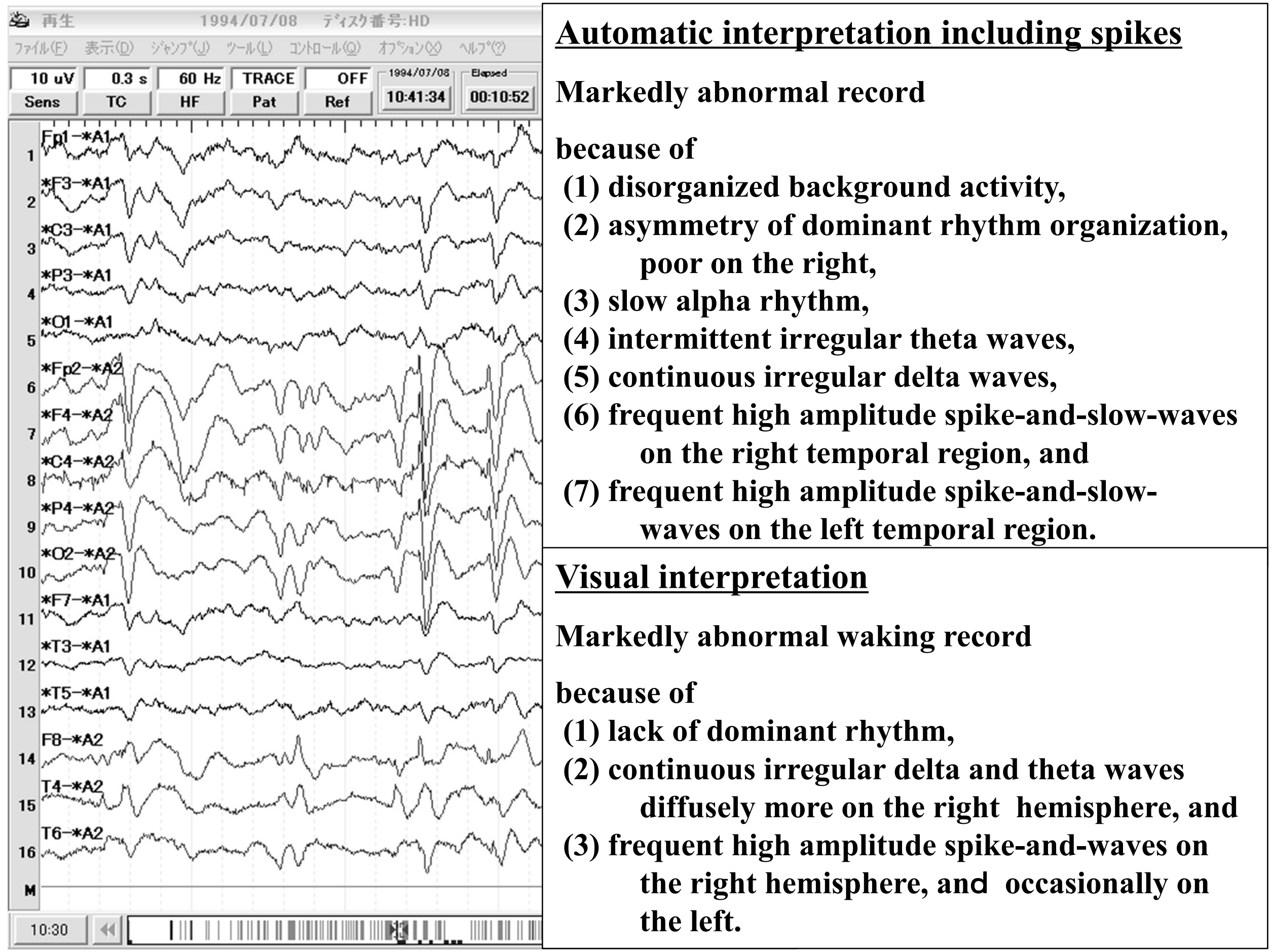




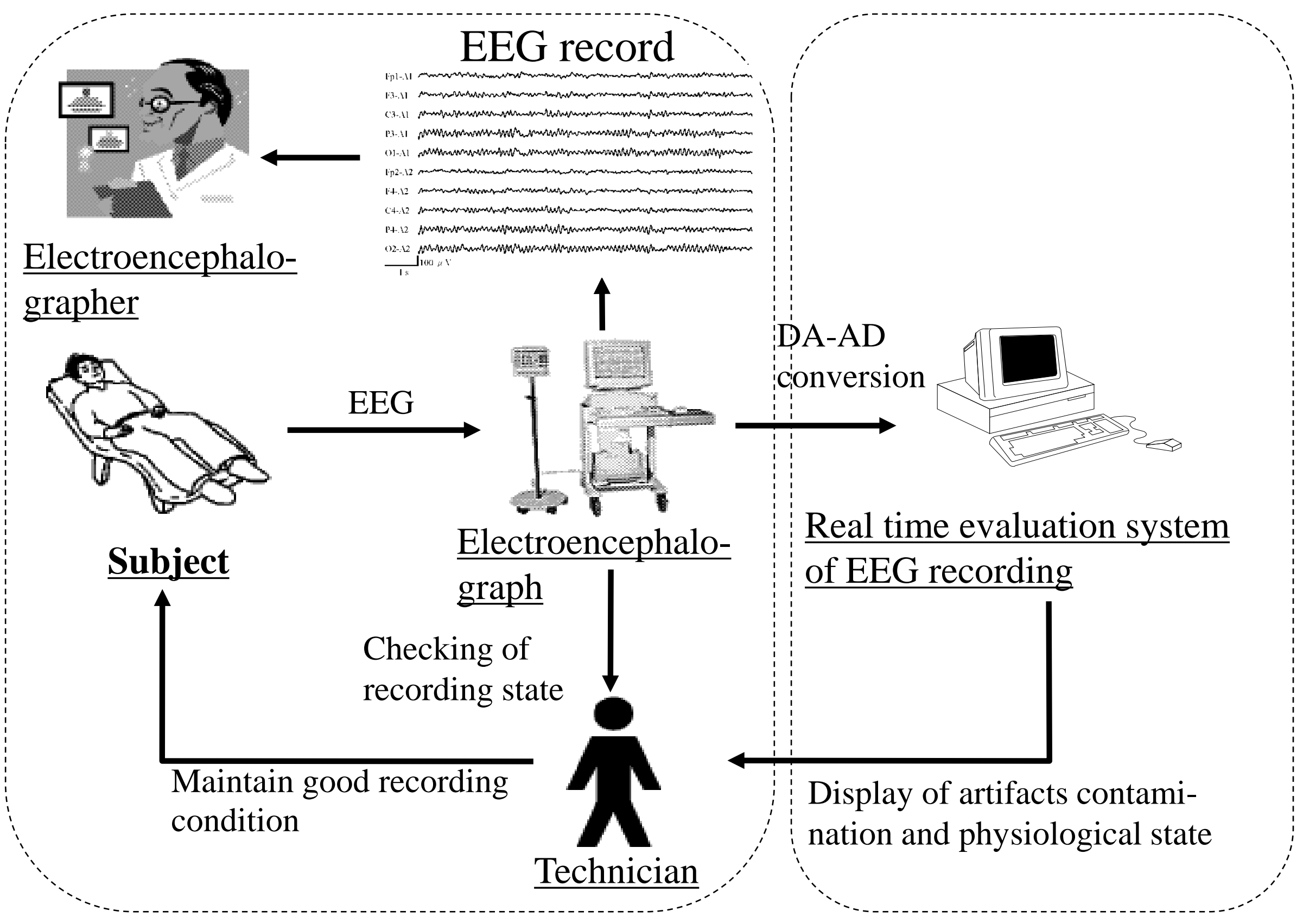


Table 1. Quantitative scoring of the adult waking EEG based on visual inspection by electroencephalographers (EEGers)

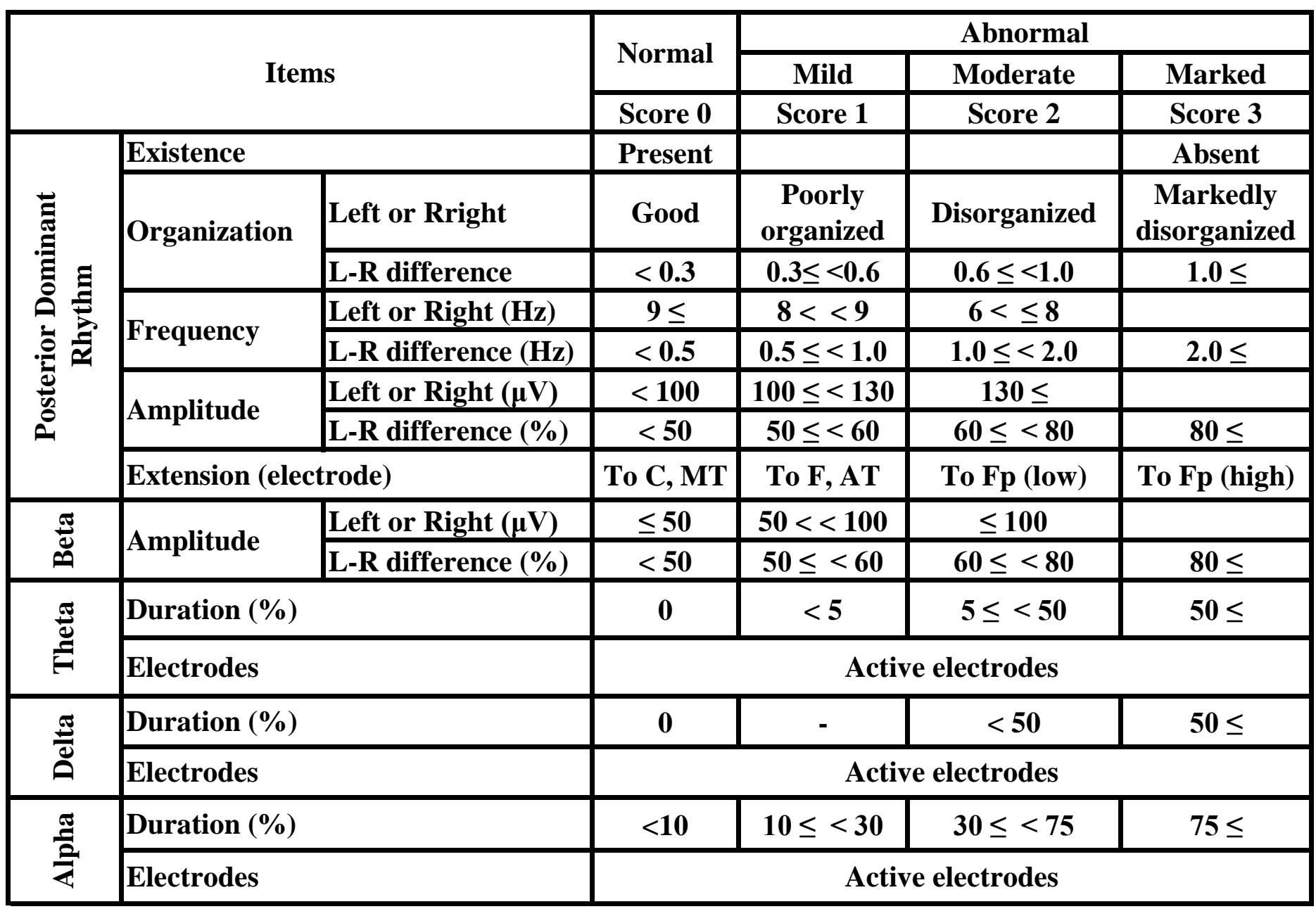

Left or Right: left or right whichever better in organization, faster in frequency or larger in amplitude

L-R difference: difference between left and right

C:central, MT: midtemporal, F: frontal, AT: anterior temporal, Fp: frontopolar

Alpha: non-dominant alpha rhythm (alpha rhythm not attributed to the posterior dominant alpha rhythm)

(Modified from Nakamura et al., 1992 with permission) 
Table 2. Equations employed for the computer-assisted calculation of parameters of each frequency band of the adult waking EEG.

\begin{tabular}{|c|c|c|c|}
\hline \multicolumn{3}{|c|}{ Items } & EEG parameters \\
\hline \multirow{7}{*}{ 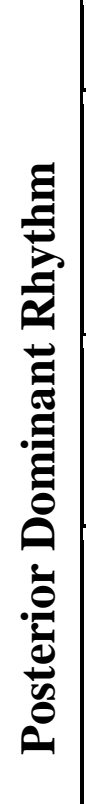 } & \multicolumn{2}{|l|}{ Existence } & ${ }_{d} / \bar{S}_{T} \geq 0.1, \quad-{ }_{d} / \tilde{S}_{d} \geq 1.0, \quad 10 \sqrt{\bar{S}_{d}} \geq 10 \mu \mathrm{V}$ \\
\hline & \multirow{2}{*}{ Organization } & Left or Right & $\begin{array}{c}y_{d}=0.49+0.58 \sigma_{\alpha}-0.13 S_{\alpha}+4.82 \times 10^{-5}\left(S_{\alpha}\right)^{2}-0.41 S_{\alpha} / S_{T} \\
+3.12 S_{\delta} / S_{T}\end{array}$ \\
\hline & & L-R difference & $\left|y_{d}\left(X_{2}\right)-y_{d}\left(X_{1}\right)\right|$ \\
\hline & \multirow{2}{*}{ Frequency } & Left or Right (Hz) & $f_{d}$ \\
\hline & & L-R difference $(\mathrm{Hz})$ & $\left|f_{d}\left(X_{2}\right)-f_{d}\left(X_{1}\right)\right|$ \\
\hline & \multirow{2}{*}{ Amplitude } & Left or Right $(\mu \mathrm{V})$ & $10 \sqrt{\bar{S}_{d}} \geq 10 \mu \mathrm{V}$ \\
\hline & & L-R difference $(\%)$ & $\left(\sqrt{-}{ }_{d}\left(X_{2}\right)-\sqrt{S_{d}}\left(X_{1}\right)\right) / \max \left\{\sqrt{S_{d}}\left(X_{1}\right), \sqrt{S_{d}}\left(X_{2}\right)\right\} \times 100$ \\
\hline & \multicolumn{2}{|l|}{ Extension } & $10 \sqrt{S_{d \prime}}$ \\
\hline \multirow{2}{*}{ 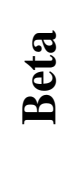 } & \multirow{2}{*}{ Amplitude } & Left or Right $(\mu V)$ & $6 \sqrt{\beta} \geq 10 \mu V$ \\
\hline & & L-R difference $(\%)$ & $\left\{S_{\beta}\left(X_{2}\right)-{ }_{\beta}\left(X_{1}\right)\right\} / \max \left\{S_{\beta}\left(X_{1}\right), \quad{ }_{\beta}\left(X_{2}\right)\right\} \times 100$ \\
\hline \multirow{2}{*}{ 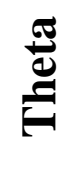 } & \multicolumn{2}{|l|}{ Duration $(\%)$} & $\left(S_{\theta} / S_{T}\right) \times 100$ if $6 \sqrt{S_{\theta}} \geq 15 \mu \mathrm{V}$ \\
\hline & \multicolumn{2}{|l|}{ Location } & Active electrodes \\
\hline \multirow{2}{*}{$\stackrel{\frac{5}{0}}{\varrho}$} & \multicolumn{2}{|l|}{ Duration $(\%)$} & $\left(S_{\delta} / S_{T}\right) \times 100$ if $6 \sqrt{S_{\delta}} \geq 25 \mu \mathrm{V}$ \\
\hline & \multicolumn{2}{|l|}{ Location } & Active electrodes \\
\hline \multirow{2}{*}{$\frac{\text { 룰 }}{2}$} & \multicolumn{2}{|l|}{ Duration $(\%)$} & $\left(S_{\alpha} / S_{T}\right) \times 100$ if $6 \sqrt{S_{\alpha}} \geq 15 \mu V$ \\
\hline & \multicolumn{2}{|l|}{ Location } & Active electrodes \\
\hline
\end{tabular}

$S d, S_{\beta}, S_{\theta}, S_{\delta}, S_{\alpha}$ : power within the respective band where $d$ is dominant rhythm and $\alpha$ is non-dominant $\alpha$ rhythm. $S_{d^{\prime}}$ : power of the dominant rhythm at anterior electrodes. $S_{T}$ : total power.

$\sigma_{\alpha}$ : standard deviation of $\alpha$ rhythm. $y_{d}$ : organization. $f_{d}$ : peak frequency of dominant rhythm.

$\mathrm{X} 1$ : left, X2: right. Otherwise the same designation as for Table 1.

(Modified from Nakamura et al., 1992 with permission) 
Table 3. Results of quantitative analysis of 10 segments of EEG, three of which are shown in Fig. 5a.

\begin{tabular}{|c|c|c|c|c|}
\hline \multicolumn{3}{|c|}{ Items } & Value & Score \\
\hline \multirow{8}{*}{ 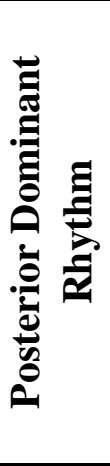 } & \multicolumn{2}{|l|}{ Existence } & Present & $\mathbf{0}$ \\
\hline & \multirow{2}{*}{ Organization } & Left or Rright & L: 1.1 R: 1.1 & 1 \\
\hline & & L-R difference & $\mathbf{0}$ & $\mathbf{0}$ \\
\hline & \multirow{2}{*}{ Frequency } & Left or Right $(\mathbf{H z})$ & L: 8.1 R: 7.9 & 1 \\
\hline & & L-R difference $(\mathrm{Hz})$ & 0.1 & $\mathbf{0}$ \\
\hline & \multirow{2}{*}{ Amplitude } & Left or Right $(\mu \mathrm{V})$ & L: 49.9 R: 57.3 & $\mathbf{0}$ \\
\hline & & L-R difference (\%) & 13.1 & $\mathbf{0}$ \\
\hline & \multicolumn{2}{|c|}{ Extension $(\boldsymbol{\mu} \mathrm{V})$} & L: 16.8 R: 20.6 & $\mathbf{0}$ \\
\hline \multirow{2}{*}{ 苞 } & \multirow{2}{*}{ Amplitude } & Left or Right $(\mu \mathrm{V})$ & 12.8 & $\mathbf{0}$ \\
\hline & & L-R difference (\%) & 26.6 & $\mathbf{0}$ \\
\hline \multirow{2}{*}{ 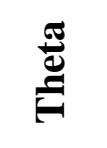 } & \multicolumn{2}{|l|}{ Duration (\%) } & 16.4 & 2 \\
\hline & \multicolumn{2}{|l|}{ Electrodes } & \multicolumn{2}{|l|}{ Fp1, F3, P3, Fp2, F4, C4, P4 } \\
\hline \multirow{2}{*}{$\frac{\pi}{\bar{D}}$} & \multicolumn{2}{|l|}{ Duration (\%) } & 14.3 & 2 \\
\hline & \multicolumn{2}{|l|}{ Electrodes } & \multicolumn{2}{|l|}{ P4 } \\
\hline \multirow{2}{*}{$\frac{\frac{\pi}{2}}{\frac{2}{2}}$} & \multicolumn{2}{|l|}{ Duration (\%) } & 8.8 & $\mathbf{0}$ \\
\hline & \multicolumn{2}{|l|}{ Electrodes } & & \\
\hline
\end{tabular}


Table 4. Written report automatically obtained as a result of quantitative analysis of 10 segments of EEG, three of which are shown in Fig. 5 a.

\section{Automatic EEG Report}

[Main report]

Moderately abnormal waking record

because of

(1)poorly organized background activity,

(2)slow alpha rhythm,

*(3) intermittent theta waves on the frontal region, and

*(4) intermittent delta waves.

[Artifacts]

Blink artifacts were present in the following segments $(1,2,4,8,10)$, and were taken into account in the interpretation.

EMG artifacts were present in the following segments $(1,2,3,4,5,6,7$, $8,9,10)$ at the electrode $\mathrm{T} 4$, and were taken into account in the interpretation.

[Remarks]

Waking record.

A1 electrode: activation by dominant rhythm was observed $(2,3,5,7)$.

A2 electrode: activation by dominant rhythm was observed $(2,3,5,7)$.

See Table 3 for the results of quantitative analysis of the same data. 